\title{
Comparison of a global-climate model to a cloud-system resolving model for the long-term response of thin stratocumulus clouds to preindustrial and present-day aerosol conditions
}

\author{
S. S. Lee and J. E. Penner \\ Department of Atmospheric, Oceanic, and Space Science, University of Michigan, Ann Arbor, MI, USA \\ Received: 23 August 2009 - Published in Atmos. Chem. Phys. Discuss.: 9 October 2009 \\ Revised: 23 June 2010 - Accepted: 30 June 2010 - Published: 14 July 2010
}

\begin{abstract}
The response of a case of thin, warm marineboundary-layer (MBL) clouds to preindustrial (PI) and present-day (PD) conditions is simulated by a cloud-system resolving model (CSRM). Here, both the aerosol conditions and environmental conditions match those of a general circulation model (GCM). The environmental conditions are characterized by the initial condition and the large-scale forcings of humidity and temperature, as well as the surface fluxes. The response of the CSRM is compared to that simulated by the GCM.

The percentage increase of liquid-water path (LWP) due to a change from the PI to PD conditions is $\sim 3$ times larger in the CSRM than that in the GCM due to the formation of cumulus clouds. The formation of cumulus clouds is controlled by a larger increase in the surface latent-heat $(\mathrm{LH})$ flux in the PD environment than in the PI environment rather than by the change in aerosols. However, the aerosol increase from the PI to PD level determines the LWP response in the stratocumulus clouds, while the impacts of changes in environmental conditions are negligible for stratocumulus clouds. The conversion of cloud liquid to rain through autoconversion and accretion plays a negligible role in the CSRM in the response to aerosols, whereas it plays a role that is as important as condensation in the GCM. Also, it is notable that the explicit simulation of microphysics in the CSRM leads to a smaller LWP in the CSRM than that in the GCM using heavily parameterized microphysics for stratocu-
\end{abstract}

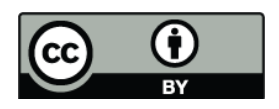

Correspondence to: S. S. Lee (seoungl@umich.edu) mulus clouds. The smaller LWP in the CSRM is closer to an observed LWP than the LWP in the GCM for stratocumulus clouds.

Supplementary simulations show that increasing aerosols increase the sensitivity of the cloud responses to the PI and PD environmental conditions. They also show that aerosol effects on clouds depend on the cloud type. The LWP of warm cumulus clouds is more sensitive to aerosols than that of stratocumulus clouds.

\section{Introduction}

Thin, warm stratocumulus clouds (with LWP $<\sim 50 \mathrm{~g} \mathrm{~m}^{-2}$ ) trapped within the MBL and aerosol-cloud interactions in these clouds may have a substantial impact on climate change. They may also account for a large portion of the uncertainty (in the prediction of climate change) associated with the aerosol indirect effect (AIE). This is because thin clouds cover $28 \%$ of the globe as shown by the International Satellite Cloud Climatology Project (ISCCP) (Rossow and Schiffer, 1999). Also, Turner et al. (2007) show that the surface and the top of the atmosphere longwave and shortwave radiative fluxes are very sensitive to small changes in the cloud LWP when the LWP is less than $\sim 50 \mathrm{~g} \mathrm{~m}^{-2}$ (see figure SB1 in Turner et al, 2007). This strong sensitivity was simulated in both summer and winter atmospheres for representative cloud-droplet effective sizes of both continental and maritime clouds. This indicates that the strong sensitivity of the radiative fluxes at low LWP was fairly robust to environmental conditions and to the size of particles. Aerosols are

Published by Copernicus Publications on behalf of the European Geosciences Union. 
known to change cloud properties including the LWP (Albrecht, 1989; Ackerman et al., 2004; Guo et al., 2007). This suggests that global radiation budgets are more susceptible to aerosol-induced changes in LWP in thin clouds than changes in LWP in comparatively thick clouds. Hence, the parameterization of these thin clouds in climate models, generally referred to as a GCM, is critical to the correct evaluation of climate change. It is important to gain a preliminary understanding of the uncertainties in simulations of thin, warm clouds in climate models in order to improve the parameterization of these clouds.

Lee et al. (2009a) compared a GCM simulation to a CSRM simulation for a thin stratocumulus cloud case. They examined the uncertainties in the cloud simulation in the climate models using the CSRM simulation as a benchmark. They performed long-term simulations over $\sim 20$ days only for PD meteorological conditions and aerosol conditions. Meteorological conditions are also referred to as environmental conditions in this study.

In general, the AIE refers to changes in cloud properties due to the increase of aerosols from the PI to the PD. The AIE is uncertain, since it accompanies changes in cloud microphysics. Uncertainties in the radiative forcing associated with the AIE are comparable to the radiative forcing due to the anthropogenic increase in green house gases (Ramaswamy et al., 2001; Forster et al., 2007). Zhang et al. (2003) stated that two lines of complication arose in the parameterization of clouds in GCMs. The first is from the spatial and temporal subgrid-scale variability of the dynamic, thermodynamic, and hydrological variables within a GCM grid box. Most GCMs (including the GCM used here) have relied on highly simplified parameterizations of subgrid-scale variables due to the use of coarse resolutions. The second is from microphysical processes associated with aerosols and hydrometeors and the representation of these processes. Hence, it is important to examine how coarse resolutions and cloud representations lead to uncertainties in the simulation of thin, warm MBL clouds associated with the AIE in GCMs. This study extends the study of Lee et al. (2009a) to the comparison of a CSRM and a GCM between simulations with PD and PI aerosols. The change in the properties of thin, warm clouds from the PI-aerosol conditions to the PD-aerosol conditions simulated in the CSRM is compared to that in the GCM in this study. This identifies why the CSRM clouds respond differently to the changing aerosol conditions as compared to the GCM clouds. This also enables us to assess uncertainties (in GCMs by cloud representations and coarse resolutions) and associated mechanisms in the prediction of changes in cloud properties and thus in climate since industrialization.

It is well known that the development of clouds is controlled by environmental factors such as the humidity and the temperature (Bluestein, 1993; Weisman and Klemp, 1982). Hence, the isolation of the effects of changing environmental conditions from those of aerosols is needed. To do this, the effects of the change in meteorology from the PI condition to the PD condition on clouds for both the PI aerosol and the PD aerosol are examined. This examination enables the examination of the sensitivity of effects of environment on clouds to aerosols. So far, most studies have focused on the effects of environmental conditions on the aerosol-cloud interactions. However, it is also likely that the effects of environmental conditions on clouds depend on aerosol levels. This is because it is expected that different nucleation due to different aerosols will induce different interactions between cloud-scale motions and environment. The different nucleation results in different droplet number and mass. This is likely to lead to the different responses of condensation and evaporation of cloud droplets and thus of microphysics and dynamics to the changing environment.

This study applies a high-resolution grid and a microphysical parameterization that includes the droplet microphysical spectral information in the CSRM. Hence, the CSRM acts as a benchmark for the assessment, in the same manner as in Lee et al. (2009a). Also, as in Lee et al. (2009a), we compare simulations over $\sim 20$ days.

\section{CSRM}

This study uses the Goddard Cumulus Ensemble (GCE) model (Tao et al., 2003) as the CSRM, which is a threedimensional nonhydrostatic compressible model. The detailed equations of the dynamical core of the GCE model are described by Tao and Simpson (1993) and Simpson and Tao (1993).

The GCE model adopts the double-moment bulk representation of Saleeby and Cotton (2004) to represent microphysical processes. Full stochastic collection solutions for self-collection among cloud droplets and for rain drop collection of cloud droplets based on Feingold et al. (1988) are obtained. The drop sedimentation as well as collection adopts the philosophy of a bin representation. The cloud droplet nucleation parameterization of Abdul-Razzak and Ghan (2000, 2002), which is based on the Köhler theory, is used. The change in mass of droplets from the vapor diffusion (i.e., condensation and evaporation) is calculated by taking into account the predicted supersaturation and cloud droplet number concentration (CDNC).

A detailed description of the model used here can be found in Lee et al. (2009a, b).

\section{GCM}

The GCM used here is the NCAR Community Atmospheric Model (CAM3) coupled with Integrated Massively Parallel Atmospheric Chemical Transport (IMPACT) aerosol model (CAM-UMICH) (Wang et al., 2009). The IMPACT aerosol model solves prognostic equations for sulfur and related species. Aerosols from biomass burning black carbon (BC) 
and natural organic matter (OM), fossil fuel $\mathrm{BC}$ and $\mathrm{OM}$, natural $\mathrm{OM}$, aircraft $\mathrm{BC}$ (soot), mineral dust, and sea salt are also included (Liu et al., 2009).

The physical parameterizations used in the standard NCAR CAM3 are documented and evaluated by Boville et al. (2006) and Collins et al. (2006). Shallow stratiform clouds, which are the cloud type of interest to us here, are parameterized following Rasch and Kristjánsson (1998) as modified by Zhang et al. (2003). In this parameterization, the stratiform condensation of cloud liquid is diagnosed based on environmental conditions such as temperature, water vapor, cloud liquid mixing ratio, and cloud fraction, which is a saturation adjustment. This is different from the condensation scheme used in the CSRM. In the CSRM, the rate of condensation is explicitly represented based on the predicted supersaturation and CDNC (see Sect. 2 and Lee et al. (2009a, b) for more detail). The conversion of cloud liquid to rain (through autoconversion and collection processes between cloud liquid and rain) follows Boucher et al. (1995) and Tripoli and Cotton (1980). A threshold mixing ratio and a constant collection efficiency with no consideration of the spectral hydrometeor information is used for the conversion.

Droplet nucleation is parameterized based on Köhler theory (Abdul-Razzak and Ghan, 2000, 2002), which is the same treatment as that used in the CSRM. The droplet selfcollection is based on the treatment of Beheng (1994).

The coupled system is run with 26 vertical levels and a $2^{\circ} \times 2.5^{\circ}$ horizontal resolution. In the MBL, the vertical grid length is $\sim 300-600 \mathrm{~m}$. The detailed description of the coupled system can be found in Lee et al. (2009a).

\section{Integration design of the CAM-UMICH model}

A pair of simulations was carried out using the coupled CAM-UMICH model. The first experiment uses PD aerosol emissions and the second uses the PI emissions. Henceforth, the first and second simulations are referred to as the "GCM-PD run" and the "GCM-PI run", respectively. The GCM-PD run used here is identical to the GCM run in Lee et al. (2009a). These GCM runs were integrated for 1 year after an initial spin-up of four months. The time step for CAM3 was $30 \mathrm{~min}$, and that for advection in IMPACT was $1 \mathrm{~h}$. Averaged boundary conditions (such as sea surface temperature, sea-ice extent, and model-top incident solar radiation) over $\sim 50$ years are used as described in Collins et al. (2006).

Anthropogenic sulfur emissions were from Smith et al. (2001, 2004), and those for the year 2000 and the year 1850 were used in the GCM-PD run and the GCM-PI run, respectively. Anthropogenic emissions of fossil fuel and biomass burning carbonaceous aerosols were from Ito and Penner (2005) but adjusted as discussed in Wang and Penner (2009). The year 2000 PD emissions included fossil fuel $\mathrm{BC}$ and $\mathrm{OM}$, and biomass burning $\mathrm{BC}$ and $\mathrm{OM}$. PI emissions were those for the year 1870. Natural emissions were the same for the PD and PI simulations. They included volcanic $\mathrm{SO}_{2}$ from Andres and Kasgnoc (1998), marine dimethylsulfide (DMS) from Kettle and Andreae (2000), OM from vegetation from Penner et al. (2001), and mineral dust. The mineral-dust emission is provided by P. Ginoux (private communication, 2004) for the year 1998 based on the algorithm of Ginoux et al. (2001). Sea salt emissions were calculated online in the coupled IMPACT-UMICH model using the method defined in Gong et al. (1997).

\section{Case descriptions and integration design of the CSRM}

The persistent development of MBL stratocumulus clouds has been observed from $\sim 30$ June to $\sim 20$ July at $\left(30^{\circ} \mathrm{N}\right.$, $120^{\circ} \mathrm{W}$ ) off the coast of the western Mexico in the GCM-PD run and the GCM-PI run. These clouds are selected for the comparison between the PI and PD simulations.

A pair of the CSRM simulations was performed. Background aerosol data for the first (second) CSRM simulation was provided by the GCM-PD (-PI) run from 16:00 LST (local solar time) on 30 June to 16:00 LST on 20 July 20 at $\left(30^{\circ} \mathrm{N}, 120^{\circ} \mathrm{W}\right)$. Henceforth, the first and second simulations are referred to as the "CSRM-PD run" and the "CSRMPI run", respectively. Note that the CSRM-PD run is identical to the CSRM run in Lee et al. (2009a). Hence, the CSRM-PD (-PI) run has the same background aerosol conditions as in the GCM-PD (-PI) run. The predicted aerosol mass of each aerosol species by the GCM runs is obtained every $6 \mathrm{~h}$. These mass data are interpolated at each time step to update the background aerosols in the CSRM runs. The aerosol mass is approximated to be uniform over the model horizontal domain and is defined to be a function of height and time only.

Initial conditions, large-scale forcings of humidity, temperature and vertical velocity, and surface fluxes were extracted from the GCM-PD (-PI) run from 16:00 LST on 30 June to $16: 00 \mathrm{LST}$ on 20 July at $\left(30^{\circ} \mathrm{N}, 120^{\circ} \mathrm{W}\right)$. These extracted environmental conditions are imposed on the CSRM runs in the same manner as in Lee et al. (2009a). This allows the CSRM-PD run and the CSRM-PI run to be performed under the same environmental conditions as those in the GCMPD and PI runs, respectively. The GCM run and CSRM run under the identical background aerosol and environmental conditions enable a comparison between the GCM run and the CSRM run (see Sect. 5 and Fig. 15 in Lee et al. (2009a) for more details). The time step of the CSRM runs is $0.5 \mathrm{~s}$.

Vertical profiles of the initial specific humidity, potential temperature, and horizontal wind velocity used in the CSRM-PD and the CSRM-PI runs can be seen in Fig. 1. The vertical distribution of the time- and area-averaged largescale forcing of temperature and humidity is shown in Fig. 2. The time series of surface fluxes imposed in the CSRM-PD and the CSRM-PI runs are depicted in Fig. 3. The profiles 
a

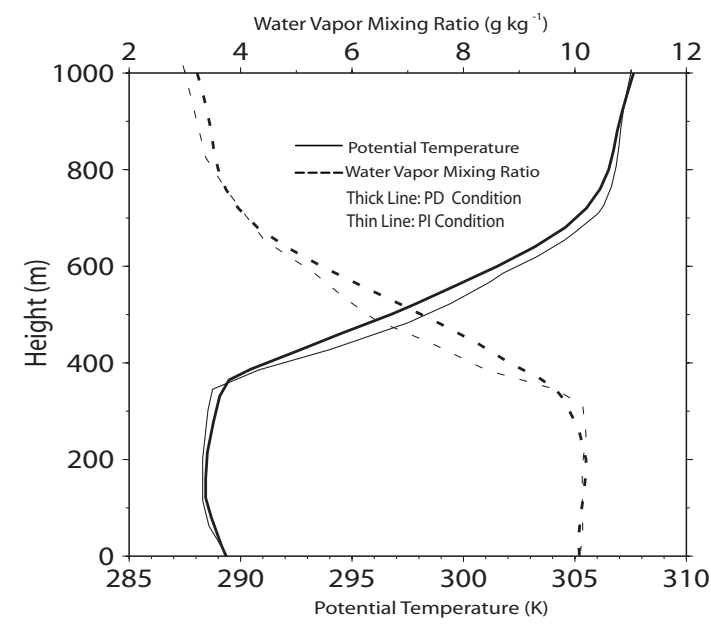

b

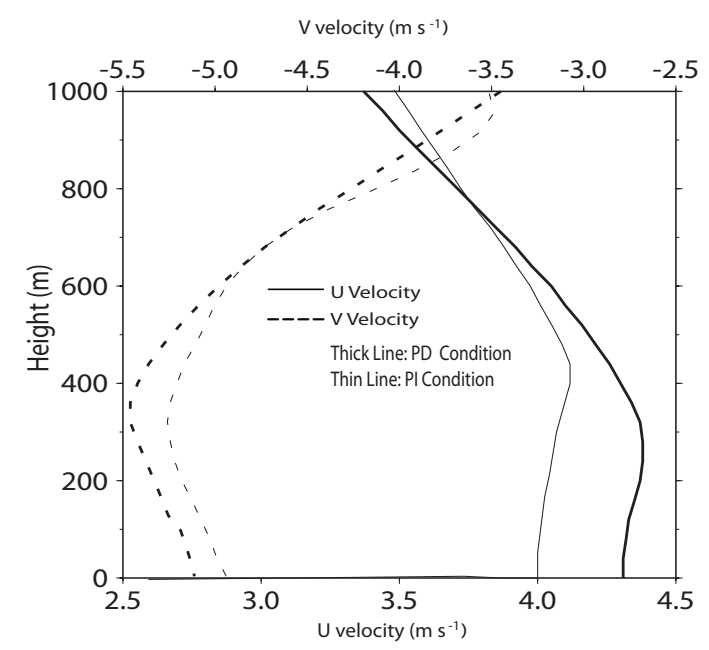

Fig. 1. Vertical profiles of (a) initial potential temperature and water vapor mixing ratio and $(\mathbf{b})$ initial horizontal wind $(u, v)$ velocity for the CSRM runs.

of humidity and potential temperature indicate that the initial inversion layer is formed around $400 \mathrm{~m}$ for both the CSRMPD run and the CSRM-PI run, respectively. Below the inversion layer, $u$ (wind in the east-west direction) and $v$ (wind in the north-south direction) velocities do not vary much. The plus and minus indicate eastward (northward) and westward (southward) wind in the $u(v)$ velocities. The maximum large-scale forcings are near $0.4 \mathrm{~km}$ for both the CSRM-PD and the CSRM-PI runs. However, these forcings are generally larger in the CSRM-PD than in the CSRM-PI run in the lower atmosphere below $\sim 1 \mathrm{~km}$ (Fig. 2). The surface LH fluxes increase significantly in the CSRM-PD run after around 00:00 LST on 13 July while the increase is much smaller in the CSRM-PI run (Fig. 3). However, the surface SH fluxes do not vary significantly throughout the simulation period for both the CSRM-PD run and the CSRM-PI run (Fig. 3). a

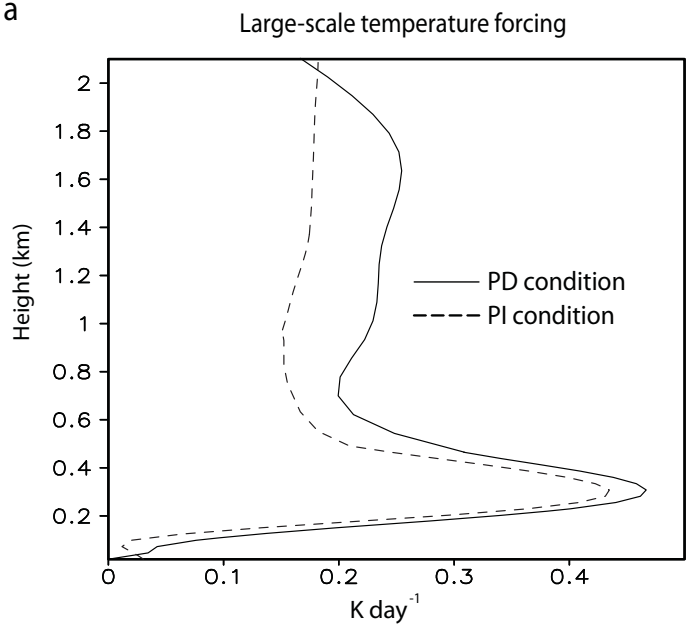

b

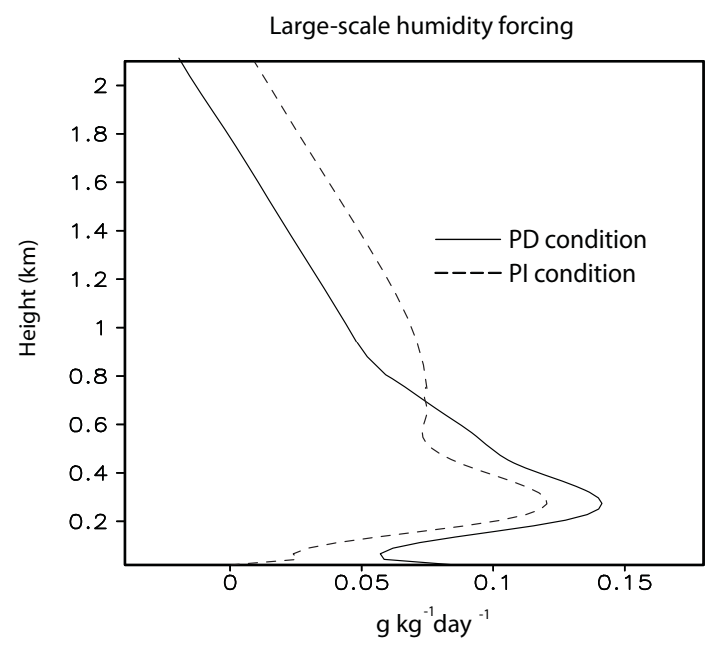

Fig. 2. Vertical distribution of the time- and area-averaged (a) potential temperature large-scale forcing $\left(\mathrm{K} \mathrm{day}^{-1}\right)$ and (b) humidity large-scale forcing $\left(\mathrm{g} \mathrm{kg}^{-1} \mathrm{day}^{-1}\right)$ for the CSRM runs.

The CSRM runs were performed in a 3-D framework. A uniform grid length of $50 \mathrm{~m}$ was used in the horizontal domain. The vertical grid length is uniformly $20 \mathrm{~m}$ below $3 \mathrm{~km}$ and then stretches to $480 \mathrm{~m}$ near the model top. Periodic boundary conditions were used for the horizontal boundaries. The horizontal domain length was set to $12 \mathrm{~km}$ in both the east-west and north-south directions in this study to capture the mesoscale structures in the CSRM runs. The vertical domain length was $20 \mathrm{~km}$ to cover the troposphere and the lower stratosphere. The justification for the discrepancy between the domain size for the CSRM runs and the size of a grid box of the GCM runs at $\left(30^{\circ} \mathrm{N}, 120^{\circ} \mathrm{W}\right.$ ) (whose horizontal domain length is $\sim 100 \mathrm{~km}$ ) is given in Sect. 5 in Lee et al. (2009a). 


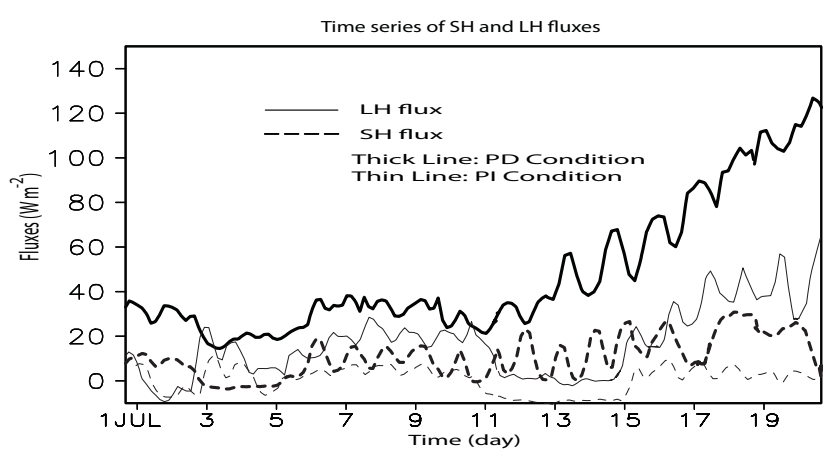

Fig. 3. Time series of the surface $\mathrm{SH}$ and $\mathrm{LH}$ fluxes $\left(\mathrm{W} \mathrm{m}^{-2}\right)$ for the CSRM runs.

Aerosol number concentrations are calculated from the mass profiles using the size distributions (mode radius, standard deviation, and partitioning of mass among modes). The size distributions are described in Chuang et al. (1997) for sulfate aerosols and Liu et al. (2005) for non-sulfate aerosols in the GCM runs. In the MBL, the background aerosol number is nearly constant and only varies vertically within $10 \%$ of its value at the surface. The time series of the vertically averaged total background aerosol number concentration in the MBL in the CSRM-PD and CSRM-PI runs is shown in Fig. 4. Generally, the aerosol number varies between 200 (100) and $700(500) \mathrm{cm}^{-3}$ for the CSRM-PD (-PI) run and is larger in the CSRM-PD run than that in the CSRM-PI run.

The treatment of aerosols within cloud follows those adopted in Lee et al. (2009a) (see section 5 in Lee et al. (2009a) for details).

Table 1 summarizes the simulations in this study. In addition to the GCM-PD and -PI runs and the CSRM-PD and -PI runs, four supplementary simulations are performed. They will be described in more detail in the following sections.

\section{Results}

\subsection{Clear-sky case}

There are differences in the parameterizations other than those used in cloud schemes between the CSRM run and the GCM run (see Collins et al., 2006; Liu et al., 2005; and Tao et al., 2003 for those differences). Hence, differences in results between the CSRM run and the GCM run may be caused not only by differences in cloud schemes but also by those in the parameterizations used for other physical and dynamical processes. Hence, comparisons between the CSRM run and the GCM run for the selected cases would not be able to isolate the effect of the cloud schemes on the simulations. Since this study focuses on the effects of different cloud parameterizations in the CSRM run and the GCM run, it is necessary to show that the results from the comparison here are robust to different schemes other than those for cloud processes.

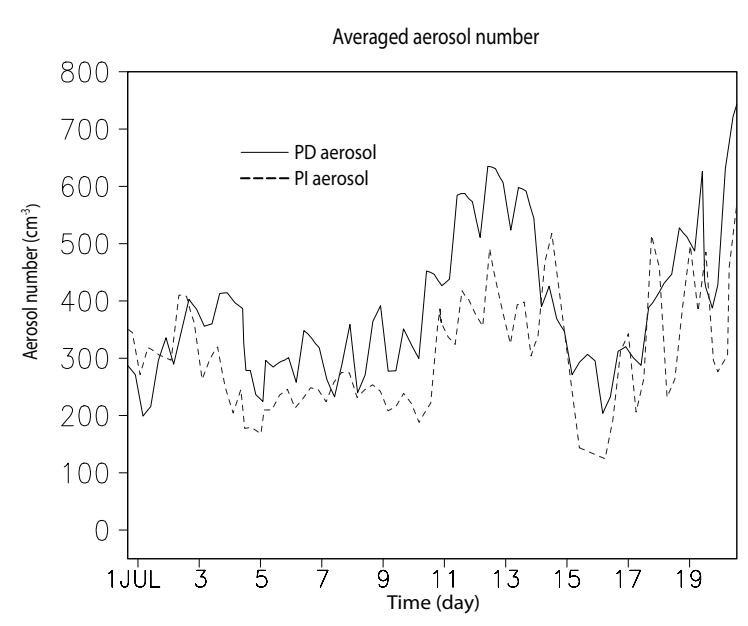

Fig. 4. Time series of background aerosol number concentration $\left(\mathrm{cm}^{-3}\right)$ averaged over the MBL in the CSRM runs.

To show this robustness, a CSRM simulation for a clearsky case was simulated by Lee et al. (2009a). They showed that the differences in the simulated fields between the CSRM run and the GCM run are negligibly small for the clear-sky case. They also showed that the different radiative properties of cloud liquid in the radiation schemes for the CSRM and the GCM had nearly identical responses to identical clouds. This demonstrated that differences in simulations between the CSRM run and the GCM run are mostly caused by differences in the cloud schemes. The detailed description of the background philosophy used here can be found in Lee et al. (2009a).

Figure $5 \mathrm{a}, \mathrm{b}$, and $\mathrm{c}$ show the vertical profile of the areaaveraged potential temperature and humidity at 00:00 LST on 11 and 15 July and 16:00 LST on 20 July, respectively, for the CSRM-PD and GCM-PD runs. These figures depict the profile above the MBL. 00:00 LST on 11 July is around the middle of time integration. 00:00 LST on 15 July is when the top height of stratocumulus clouds is at its maximum in the CSRM-PD run. 16:00 LST on 20 July is at the end of simulations (see Fig. 7a in Lee et al. (2009a) for the stage of cloud development). Nearly identical vertical temperature and humidity in the CSRM-PD run to those in the GCM-PD run are shown in Fig. 5a and b. The differences in temperature and humidity around the MBL top between the CSRM-PD run and the GCM-PD run in Fig. 5c are rather large as compared to those in Fig. 5a and b. However, these differences in Fig. $5 \mathrm{c}$ are found to be small enough to demonstrate that the comparison between a CSRM run and a GCM run for clouds can be restricted to layers below the top of the MBL. Our test simulations show that the effect of those differences on cloud development is not significant. 
Table 1. Summary of simulations.

\begin{tabular}{|c|c|c|c|c|c|}
\hline Simulation & Model & Location & Period & Aerosol & Environment \\
\hline GCM-PD run & $\begin{array}{l}\text { IMPACT- } \\
\text { CAM } \\
\text { Model }\end{array}$ & Globe & $\begin{array}{l}\text { One year after the spin- } \\
\text { up time of four months }\end{array}$ & $\begin{array}{l}\text { Globally predicted with } \\
\text { the PD aerosol } \\
\text { emissions }\end{array}$ & $\begin{array}{l}\text { The PD environme nt is } \\
\text { produced }\end{array}$ \\
\hline GCM-PI run & $\begin{array}{l}\text { IMPACT- } \\
\text { CAM } \\
\text { Model }\end{array}$ & Globe & $\begin{array}{l}\text { One year after the spin- } \\
\text { up time of four months }\end{array}$ & $\begin{array}{l}\text { Globally predicted with } \\
\text { the PI aerosol } \\
\text { emissions }\end{array}$ & $\begin{array}{l}\text { The PI environment is } \\
\text { produced }\end{array}$ \\
\hline $\begin{array}{l}\text { GCM-E(PD)- } \\
A(P I) \text { run }\end{array}$ & $\begin{array}{l}\text { Single-column } \\
\text { model }\end{array}$ & $\begin{array}{l}\left(30^{\circ} \mathrm{N}\right. \\
\left.120^{\circ} \mathrm{W}\right)\end{array}$ & 30 June to 17 July & $\begin{array}{l}\text { The PI aerosol at } \\
\left(30^{\circ} \mathrm{N}, 120^{\circ} \mathrm{W}\right)\end{array}$ & $\begin{array}{l}\text { The PD environment at } \\
\left(30^{\circ} \mathrm{N}, 120^{\circ} \mathrm{W}\right)\end{array}$ \\
\hline $\begin{array}{l}\text { GCM-E(PI)- } \\
A(P D) \text { run }\end{array}$ & $\begin{array}{l}\text { Single-column } \\
\text { model }\end{array}$ & $\begin{array}{l}\left(30^{\circ} \mathrm{N}\right. \\
\left.120^{\circ} \mathrm{W}\right)\end{array}$ & 30 June to 17 July & $\begin{array}{l}\text { The PD aerosol at } \\
\left(30^{\circ} \mathrm{N}, 120^{\circ} \mathrm{W}\right)\end{array}$ & $\begin{array}{l}\text { The PI environme nt at } \\
\left(30^{\circ} \mathrm{N}, 120^{\circ} \mathrm{W}\right)\end{array}$ \\
\hline CSRM-PD run & $\begin{array}{l}\text { GCE } \\
\text { model }\end{array}$ & $\begin{array}{l}\left(30^{\circ} \mathrm{N}\right. \\
\left.120^{\circ} \mathrm{W}\right)\end{array}$ & 30 June to 20 July & $\begin{array}{l}\text { The PD aerosol at } \\
\left(30^{\circ} \mathrm{N}, 120^{\circ} \mathrm{W}\right)\end{array}$ & $\begin{array}{l}\text { The PD environment at } \\
\left(30^{\circ} \mathrm{N}, 120^{\circ} \mathrm{W}\right)\end{array}$ \\
\hline CSRM-PI run & $\begin{array}{l}\text { GCE } \\
\text { model }\end{array}$ & $\begin{array}{l}\left(30^{\circ} \mathrm{N}\right. \\
\left.120^{\circ} \mathrm{W}\right)\end{array}$ & 30 June to 20 July & $\begin{array}{l}\text { The PI aerosol at } \\
\left(30^{\circ} \mathrm{N}, 120^{\circ} \mathrm{W}\right)\end{array}$ & $\begin{array}{l}\text { The PI environment at } \\
\left(30^{\circ} \mathrm{N}, 120^{\circ} \mathrm{W}\right)\end{array}$ \\
\hline $\begin{array}{l}\text { CSRM-E(PD)- } \\
A(P I) \text { run }\end{array}$ & $\begin{array}{l}\text { GCE } \\
\text { model }\end{array}$ & $\begin{array}{l}\left(30^{\circ} \mathrm{N}\right. \\
\left.120^{\circ} \mathrm{W}\right)\end{array}$ & 30 June to 20 July & $\begin{array}{l}\text { The PI aerosol at } \\
\left(30^{\circ} \mathrm{N}, 120^{\circ} \mathrm{W}\right)\end{array}$ & $\begin{array}{l}\text { The PD environment at } \\
\left(30^{\circ} \mathrm{N}, 120^{\circ} \mathrm{W}\right)\end{array}$ \\
\hline $\begin{array}{l}\text { CSRM-E(PI)- } \\
A(P D) \text { run }\end{array}$ & $\begin{array}{l}\text { GCE } \\
\text { model }\end{array}$ & $\begin{array}{l}\left(30^{\circ} \mathrm{N}\right. \\
\left.120^{\circ} \mathrm{W}\right)\end{array}$ & 30 June to 20 July & $\begin{array}{l}\text { The PD aerosol at } \\
\left(30^{\circ} \mathrm{N}, 120^{\circ} \mathrm{W}\right)\end{array}$ & $\begin{array}{l}\text { The PI environme nt at } \\
\left(30^{\circ} \mathrm{N}, 120^{\circ} \mathrm{W}\right)\end{array}$ \\
\hline
\end{tabular}

\subsection{Cloud properties and comparison with observation}

Figure $6 \mathrm{a}, \mathrm{b}, \mathrm{c}$, and $\mathrm{d}$ show a time-height cross section of cloud-liquid mixing ratio for the CSRM-PD, GCM-PD, CSRM-PI, and GCM-PI runs. Figure 6e shows a time-height cross section of cloud-liquid mixing ratio for one of the supplementary simulations which will be described in the following sections. Figure 7 shows the time series of LWPs for the GCM-PD and -PI runs, and the CSRM-PD and -PI runs, smoothed over 1 day (averaged over the period between $12 \mathrm{~h}$ before and after a time point). LWP in the GCM-PD run generally shows much larger temporal fluctuations than the CSRM-PD-run LWP.

Table 2 shows the time- and domain-averaged GCM and CSRM LWP and the time-averaged LWP observed by the Moderate Resolution Imaging Spectroradiometer (MODIS) on the Terra satellite. The MODIS LWP is provided as averaged values for each day (for the 10:30 a.m. crossing time for July 2001 to 2008). The LWP in the CSRM-PD run can be considered closer to that observed by the MODIS than that in the GCM-PD run considering the LWPs in these runs averaged over entire simulation period. Both the GCM and the CSRM have the larger LWPs in the PD runs than in the
PI runs over the entire simulation period. However, the differences in the LWP between the PD run and the PI run in the GCM differ from those in the CSRM. There is a $71 \%$ increase in LWP in the CSRM runs in the PD case compared to the PI case, while there is only a $23 \%$ increase in the LWP in the GCM runs. This is also shown in the diagonal arrows in Fig. 8a. Arrows for the GCM and CSRM runs in Fig. 8 provide the diagrammatic depiction of the percentage variations of LWP for the entire simulation period. The depiction by the diagonal arrows is for the LWP variations with simultaneously varying environment and aerosol conditions. Also, LWP is significantly different between the GCM-PI (-PD) run and the CSRM-PI (-PD) run. The GCM has a 66 (132) $\%$ larger LWP than the CSRM in the PD (PI) condition (over the entire simulation period).

Table 2 also shows the in-cloud average effective radius of droplets and the average cloud fraction. Conditional averages (over cloudy regions) at every time step were obtained for the in-cloud average effective radius. Only those time steps with a non-zero conditionally averaged effective radius were included in the in-cloud average. The conditional average is the arithmetic mean of the variable over all in-cloud grid points (grid points in clear air are excluded from the average). 
Table 2. Averaged LWP, effective radius, and cloud fraction. The standard deviations of LWP and effective radius in MODIS, the GCM-PD and the CSRM-PD simulations are shown in parentheses for the corresponding average periods.

\begin{tabular}{|c|c|c|c|c|c|c|c|c|c|}
\hline & \multicolumn{3}{|c|}{ Time- and area-averaged $\operatorname{LWP}\left(\mathrm{g} \mathrm{m}^{-2}\right)$} & \multicolumn{3}{|c|}{ In-cloud average effective radius $(\mu \mathrm{m})$} & \multicolumn{3}{|c|}{ Time-averaged cloud fraction } \\
\hline & $\begin{array}{l}\text { Entire } \\
\text { Period }\end{array}$ & $\begin{array}{l}\text { Before 00:00 } \\
\text { LST 17 July }\end{array}$ & $\begin{array}{l}\text { After 00:00 } \\
\text { LST 17 July }\end{array}$ & $\begin{array}{l}\text { Entire } \\
\text { Period }\end{array}$ & $\begin{array}{l}\text { Before 00:00 } \\
\text { LST 17 July }\end{array}$ & $\begin{array}{r}\text { After 00:00 } \\
\text { LST 17 July }\end{array}$ & $\begin{array}{l}\text { Entire } \\
\text { Period }\end{array}$ & Before 00:00 & After 00:00 \\
\hline MODIS Simulation & $13.7(8.0)$ & $12.3(6.1)$ & $26.2(12.5)$ & $7.7(1.8)$ & $7.7(2.3)$ & $7.8(0.7)$ & - & - & - \\
\hline GCM-PD & $20.3(14.0)$ & $24.3(18.2)$ & $7.6(4.2)$ & $7.2(1.7)$ & $7.4(2.0)$ & $5.5(0.9)$ & 0.59 & 0.59 & 0.55 \\
\hline GCM-PI & 16.5 & 16.3 & 17.8 & 7.3 & 7.5 & 5.7 & 0.57 & 0.57 & 0.54 \\
\hline GCM-E(PD)-A(PI) & - & 21.9 & - & - & 7.5 & - & - & 0.58 & - \\
\hline GCM-E(PI)-A(PD) & - & 19.1 & - & - & 7.4 & - & - & 0.58 & - \\
\hline CSRM-PD & $12.2(9.3)$ & $10.3(6.3)$ & $30.3(16.7)$ & $7.8(2.2)$ & $7.8(2.3)$ & $7.5(2.0)$ & 0.62 & 0.61 & 0.75 \\
\hline CSRM-PI & 7.1 & 7.3 & 3.1 & 7.8 & 7.8 & 7.3 & 0.60 & 0.59 & 0.65 \\
\hline CSRM-E(PD)-A(PI) & 8.0 & 7.4 & 18.5 & 7.9 & 7.9 & 7.6 & 0.61 & 0.60 & 0.70 \\
\hline CSRM-E(PI)-A(PD) & 9.8 & 10.1 & 3.2 & 7.7 & 7.7 & 7.2 & 0.62 & 0.61 & 0.67 \\
\hline
\end{tabular}

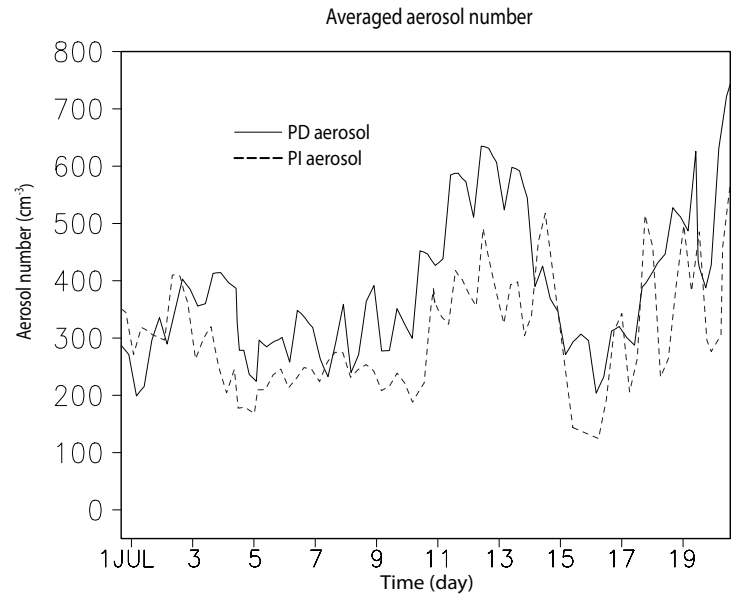

Fig. 5. Vertical profiles of the area-averaged potential temperature and water-vapor mixing ratio at (a) 00:00 LST on 11 July, (b) 00:00 LST on 15 July, and (c) 16:00 LST on 20 July for CSRM- and GCM-PD runs.

For the calculation of the conditional average over cloudy regions, it is necessary to determine which grid points are in cloud. Grid points are assumed to be in cloud if the number concentration and volume-mean size of droplets is typical for clouds and fogs $\left(1 \mathrm{~cm}^{-3}\right.$ or more, $1 \mu \mathrm{m}$ or more; Pruppacher and Klett, 1997). The cloud fraction, however, was averaged over all time steps and the layer between minimum cloudbase height and maximum cloud-top height in the CSRM and GCM runs when clouds are present. In general, the CSRMPD-run effective size is closer to the MODIS-observed size than the GCM-PD-run size. The effective radius decreases by less than 2 (1) $\%$ and the cloud fraction increases by $\sim 4$ (3) \% between the PI and the PD conditions in the set of the GCM (CSRM) runs. These decreases and increases are much smaller than the increase in LWP. Differences in the radius and cloud fractions between the GCM-PI (-PD) runs and

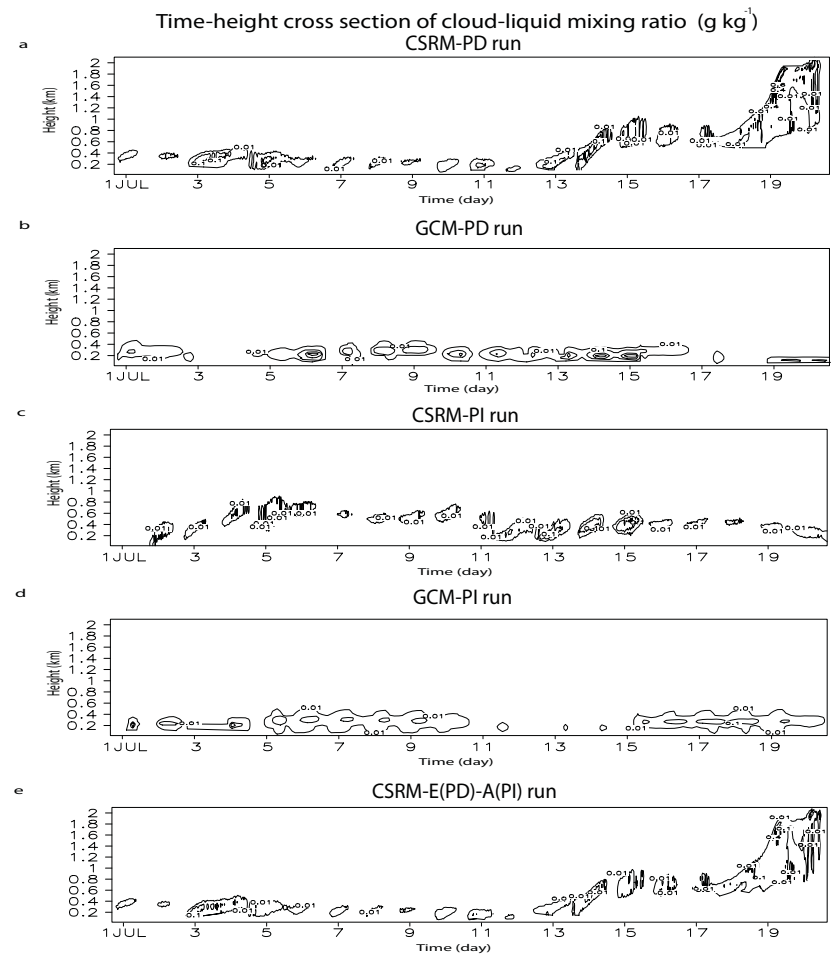

Fig. 6. Time-height cross section of cloud-liquid mixing ratio (g $\mathrm{kg}^{-1}$ ) for (a) the CSRM-PD run, (b) the GCM-PD run, (c) the CSRM-PI run, (d) the GCM-PI run, (e) the CSRM-E(PD)-A(PI) run. Contours are at $0.01,0.1,0.4$, and $0.6 \mathrm{~g} \mathrm{~kg}^{-1}$ for the period before 00:00 LST on 17 July in the CSRM-PD run and for the entire period in the GCM-PD and -PI runs and the CSRM-PI run. For the period after 00:00 LST on 17 July in the CSRM-PD run, contours are at $0.01,0.4$, and $0.6 \mathrm{~g} \mathrm{~kg}^{-1}$.

the CSRM-PI (-PD) runs are smaller than $\sim 5 \%$. Hence, the change in the cloud radiative properties is mainly controlled by the change in the LWP in the simulations. The larger LWP 


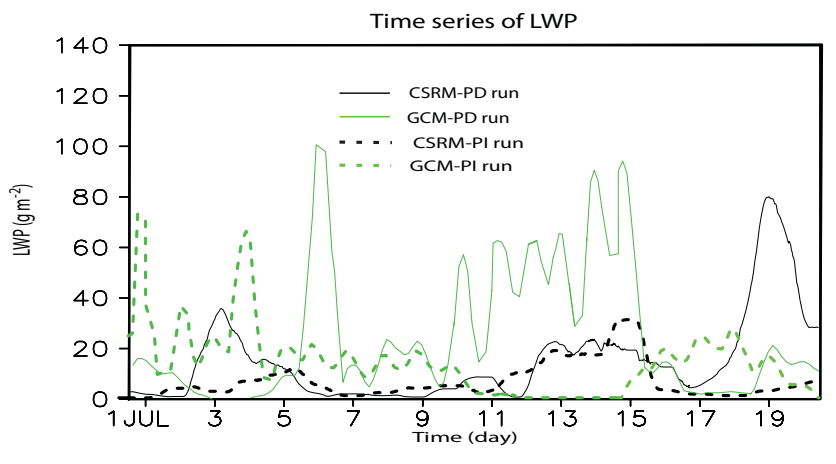

Fig. 7. Time series of LWP $\left(\mathrm{g} \mathrm{m}^{-2}\right)$ averaged over the horizontal domain for the CSRM runs and the GCM runs.

reflects more incident shortwave radiation. This leads to smaller time- and area-averaged net downward shortwave radiation in the GCM-PI (-PD) run than in the CSRM-PI (-PD) run at the top of the atmosphere. The net downward shortwave radiation is $357.5(340.2)$ and $451.8(408.4) \mathrm{W} \mathrm{m}^{-2}$ for the GCM-PI (-PD) run and the CSRM-PI (-PD) run, respectively. Thus, we can also see that a 2 times larger percentage variation in the change in the net downward radiation in the PD and PI runs due to the larger variation in the LWP in the CSRM runs than in the GCM runs.

\subsection{Liquid-water budget of stratocumulus clouds}

A smaller time- and domain-averaged LWP is simulated in the CSRM run than in the GCM run for both the PD and the PI conditions over the entire simulation period. This is mostly due to the smaller averaged LWP when stratocumulus clouds are a dominant cloud type in all of the GCM runs and CSRM runs before 00:00 LST on 17 July (Table 2). After 00:00 LST on 17 July, cumulus clouds develop in the CSRM run with the PD environment and this will be discussed in Sect. 6.4. The percentage increase in the LWP from the PI simulation to the PD simulation is also smaller in the CSRM runs than in the GCM runs in stratocumulus clouds (before 00:00 LST on 17 July). This can be seen in the diagonal arrows in Fig. $8 \mathrm{~b}$ and Table 2. This leads to a smaller percentage decrease in the time- and domain- averaged net downward shortwave radiation at the top of the atmosphere from the PI simulation to the PD simulation in the CSRM runs than in the GCM runs. The averaged net shortwave radiation fluxes (which is downward) at the top of the atmosphere over the period between 16:00 LST on 30 June and 00:00 LST on 17 July are obtained. They are 448.9 (423.6) and 358.6 (324.3) $\mathrm{W} \mathrm{m}^{-2}$ in the PI (PD) simulation for the CSRM and GCM runs, respectively. The diagnosed shortwave cloud forcings (SCFs) are $-12(-37)$ and $-103(-137) \mathrm{W} \mathrm{m}^{-2}$ in the PI (PD) simulation for the CSRM and GCM runs, respectively. The magnitude of variation of SCF is larger mainly due to the larger change in LWP in the GCM runs than in the CSRM runs with the PI-to-PD variation. However, the cor- responding percentage variation of SCF is much smaller in the GCM runs than in the CSRM runs. The SCF percentage variation is $\sim 30$ and $200 \%$ for the GCM and CSRM runs, respectively. Mechanisms which lead to the different LWPs and their variation with the PI-to-PD changes in aerosols and environment in stratocumulus clouds between the CSRM and the GCM are examined. These mechanisms are very likely to be linked to the use of different microphysics parameterizations and resolutions between the CSRM and the GCM. The analyses of the liquid-water budget terms of the CSRM runs and the GCM runs are performed to identify these mechanisms and their links to parameterizations and resolutions. Also, the role of aerosols in the LWP variation with the PIto-PD changes is compared to that of the environment for stratocumulus clouds.

\subsubsection{Cloud-liquid budget}

The averaged LWPs over the period before 00:00 LST on 17 July are less than $50 \mathrm{~g} \mathrm{~m}^{-2}$ for the CSRM and GCM runs (Table 2). Hence, stratocumulus clouds here can be considered thin according to the classification of Turner et al. (2007).

To elucidate the microphysical processes controlling the liquid-water content (LWC) and thus LWP of the stratocumulus clouds in the CSRM and GCM runs, the domainaveraged cumulative source (i.e., condensation) and sinks of cloud liquid were obtained. For this, the production equation for cloud liquid was integrated over the domain and over the period before 00:00 LST on 17 July for both the CSRM and GCM runs. These integrations are denoted by $<\quad>$ :

$$
<A>=\frac{1}{L x L y} \iiint \rho_{a} A d x d y d z d t
$$

where $L x$ and $L y$ are the domain length $(12 \mathrm{~km})$, in the eastwest and north-south directions, respectively. $\rho_{a}$ is the air density and $A$ represents any of the variables in this study. The budget equation for cloud liquid is as follows:

$<\frac{\partial q_{c}}{\partial t}>=<Q_{\text {cond }}>-<Q_{\text {evap }}>-<Q_{\text {auto }}>-<Q_{\text {accr }}>$

Here, $q_{c}$ is the cloud-liquid mixing ratio. $Q_{\text {cond }}, Q_{\text {evap }}$, $Q_{\text {auto }}$, and $Q_{\text {accr }}$ refer to the rates of condensation, evaporation, autoconversion of cloud liquid to rain, and accretion of cloud liquid by rain, respectively.

Table 3 shows the budget from Eq. (2) for the CSRM-PD and -PI runs and GCM-PD and -PI runs. The other runs in Table 3 will be discussed in the following sections. The budget results show that condensation and evaporation are one to three orders of magnitude larger than autoconversion and accretion for both the CSRM-PD run and the CSRM-PI run. This indicates that the conversion of cloud liquid (produced by condensation) to rain is highly inefficient as was the case in the thin clouds simulated by Lee et al. (2009b). However, for both the GCM-PD and GCM-PI runs, the conversion of cloud liquid to rain plays just as important roles as does condensation in the determination of LWP (Fig. 9a and b and Table 3). 
Table 3. Domain-averaged budget terms of cloud liquid $(\mathrm{mm})$ during the time period when stratocumulus clouds dominate before 00:00 LST on 17 July.

\begin{tabular}{lrrrrr}
\hline & $<\frac{\partial q_{c}}{\partial t}>$ & $\begin{array}{r}<Q_{\text {cond }}> \\
\text { Condensation }\end{array}$ & $\begin{array}{r}<Q_{\text {evap }}> \\
\text { Evaporation }\end{array}$ & $\begin{array}{r}<Q_{\text {auto }}>\text { Autoconversion } \\
\text { of cloud liquid to rain }\end{array}$ & $\begin{array}{r}<Q_{\text {accr }}>\text { Accretion of } \\
\text { cloud liquid by rain }\end{array}$ \\
\hline GCM-PD & -0.0130 & 1.6410 & 1.0190 & 0.022 & 0.613 \\
GCM-PI & -0.0010 & 1.2610 & 0.4410 & 0.063 & 0.758 \\
GCM-E(PD)-A(PI) & -0.0151 & 1.6290 & 0.8121 & 0.058 & 0.774 \\
GCM-E(PI)-A(PD) & -0.0009 & 1.2533 & 0.6272 & 0.019 & 0.608 \\
CSRM-PD & 0.0050 & 0.6250 & 0.6125 & 0.00029 & 0.0072 \\
CSRM-PI & 0.0020 & 0.4250 & 0.4106 & 0.00040 & 0.012 \\
CSRM-E(PD)-A(PI) & 0.0054 & 0.4451 & 0.4243 & 0.00042 & 0.015 \\
CSRM-E(PI)-A(PD) & 0.0059 & 0.6103 & 0.5901 & 0.00027 & 0.014 \\
\hline
\end{tabular}

The small contribution of autoconversion and accretion to the LWC implies that the role of sedimentation of cloud particles (cloud liquid+rain) in the determination of LWC is not as significant as that of condensation and evaporation in the CSRM runs. This is due to the positive relation between the particle terminal velocity, size, and sedimentation described in Lee et al. (2009a, b).

Also, there are much larger differences in condensation and evaporation as compared to those in autoconversion and accretion between the CSRM-PD run and the CSRM-PI run (Table 3). The variation in autoconversion and accretion accounts for only $\sim 2 \%$ of the variation of condensation between the CSRM-PD run and the CSRM-PI run. This implies that the variation of sedimentation (associated with that of autoconversion and accretion) is much smaller than that of condensation and evaporation due to the change from the PI condition to the PD condition. In contrast, Fig. 9a and $\mathrm{b}$ and Table 3 show that the variation in the conversion of cloud liquid to rain (i.e., autoconversion + collection) between the PI and PD conditions accounts for $\sim 50 \%$ of the variation of condensation between the GCM-PD run and the GCM-PI run. Due to this larger decrease in conversion, the GCM-PD run shows a larger percentage increase $(49 \%)$ in the LWP than that in the CSRM-PD run $(41 \%$ ) (see the diagonal arrows in Fig. 8b). This is despite the smaller increase in condensation between the PI run and the PD run before 00:00 LST on 17 July when stratocumulus clouds dominate for the GCM-PD, -PI, CSRM-PD, and -PI runs (Tables 2 and 3 ).

Figure 9d, e, and $\mathrm{f}$ show the vertical distribution of the time- and area-averaged condensation, conversion of cloud liquid to rain, and liquid-mass changes due to sedimentation for the CSRM-PD run and the CSRM-PI run before 00:00 LST on 17 July. The CSRM-E(PD)-A(PI) run in Fig. 9e will be described in the following sections. Liquid mass here is the sum of the mass of all species associated with warm microphysics, i.e., cloud liquid and rain. The magnitude of the condensation rate is substantially larger than that of conversion of cloud liquid to rain and thus the sedimentation-induced liquid-mass changes for both of the CSRM-PD run and the CSRM-PI run. Also, the magnitude of difference in the condensation rate between the CSRM-PD run and the CSRM-PI run is substantially larger than that in conversion of cloud liquid to rain and thus in sedimentationinduced mass changes. Hence, as implied by the budget analysis, LWC and LWP and their responses to the change from PI to PD conditions are strongly controlled by condensation while the role of sedimentation in their determination is negligible due to the inefficient conversion of cloud liquid to rain. However, as seen in comparisons between Fig. 9a and c (depicting sedimentation-induced liquid-mass changes for the GCM runs), sedimentation in the GCM-PD and GCMPI runs accounts for a significant portion of condensation in the GCM-PD and GCM-PI runs, respectively. Also, the sedimentation difference between the GCM-PD run and the GCM-PI run accounts for a significant portion of the condensation difference between the GCM-PD run and the GCM-PI run. This is due to an efficient conversion of cloud liquid to rain as compared to that in the CSRM runs.

Small cloud droplets grow to a critical size for (active) collection not only by the turbulent collisions among them but also by condensation. For particles smaller than the critical size, condensational growth is as important as the growth through the turbulent collisions. These small particles grow via positive feedbacks between the condensational growth and the growth through these turbulent collisions. However, above the critical size, the growth through collection is dominant (Rogers and Yau, 1991). Thus, it is likely that, as clouds get thinner, these feedbacks get weaker and thus the conversion efficiency (i.e., the ratio between the conversion of cloud liquid to rain and condensation) gets lower. This is because condensation in thinner clouds with lower LWP is likely to be lower. Hence, for the thin stratocumulus clouds simulated here, the conversion of droplets to rain (here, defined as particles whose radius is larger than 40 micron) is inactive enough to result in nearly inactive sedimentation as compared to 
a Entire simulation period

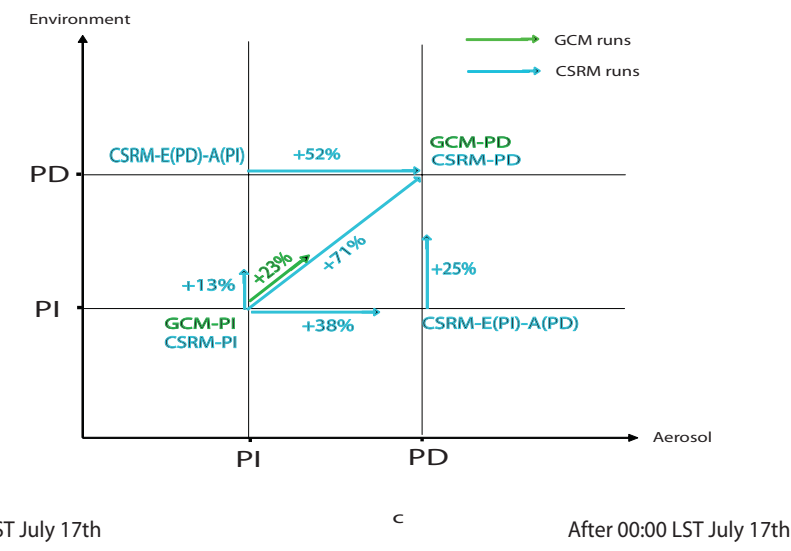

c

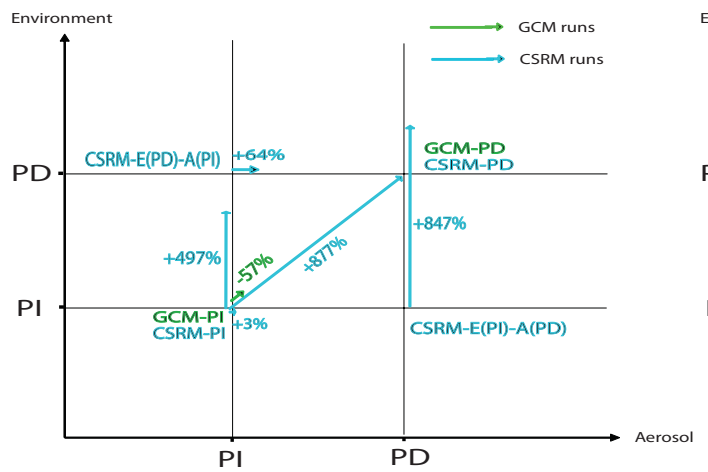

After 00:00 LST July 17 th

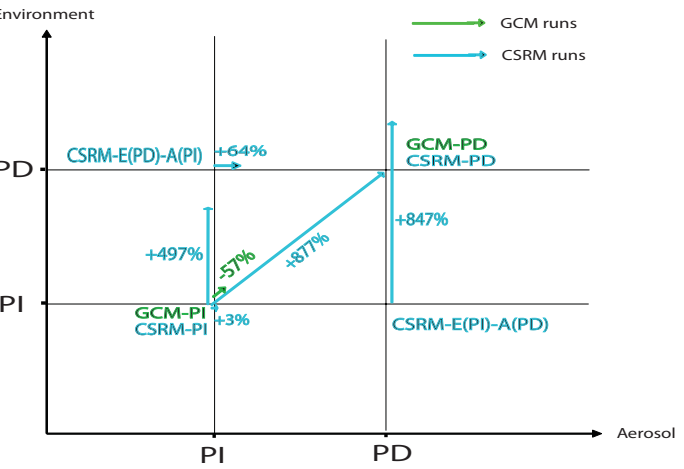

Fig. 8. Schematic diagrams illustrating the percentage change in LWP due to changes in the environment and aerosols. (a), (b), and (c) are for the entire simulation period and the period before and after 00:00 LST on 17 July, respectively. The abscissa and the ordinate represent the environment and the aerosol conditions, respectively, and PI and PD represent the preindustrial and present-day conditions, respectively. Each of arrows represents the magnitude of the percentage changes (proportional to an arrow length) in LWP and the direction of changes in conditions (indicated by an arrowhead). The green and blue arrows represent these changes in the GCM and the CSRM simulations, respectively. The arrow length is scaled relative to the longest arrow (the diagonal blue arrow for (a) and (c) and the diagonal green arrow for (b)) in each figure. The two horizontal (vertical) arrows are for changes in LWP due to changes in aerosols (the environment) from the PI condition to the PD condition at either the PI environment (aerosol), represented by the lower (left) arrow, or the PD environment (aerosol), represented by the upper (right) arrow. The diagonal arrow is for the LWP change due to simultaneous changes in aerosol and environment from the PI conditions to the PD conditions. For reference, the value of the percentage variation of LWP is shown near a corresponding arrow. The plus and minus in the value indicate an increase and a decrease in LWP, respectively. The names of experiments from which LWP values are produced to calculate a LWP change are shown around the starting point and in front of an arrowhead of a corresponding arrow.

condensation in the CSRM runs. Also, Khairoutdinov and Kogan (2000) indicated that the sensitivity of the conversion of cloud liquid to rain to varying CDNC was weaker at low LWC than at high LWC. This is based on results from a bin model which takes into account the feedbacks between condensation and collisions. Their finding implies that the sensitivity of sedimentation to aerosol changes (leading to CDNC changes) is also weaker at low LWC. The variation of the conversion of cloud droplets to rain with varying aerosols is not large enough to make a significant difference in the sedimentation of cloud particles among simulations with low LWC here in the CSRM runs. This leads to a negligible role of sedimentation in the response of LWP to aerosols as com- pared to that of condensation. The parameterizations used in the CSRM are able to simulate the feedbacks between condensation and collision explicitly when particles are smaller than the critical size. This is because these parameterizations are able to predict supersaturation and CDNC and consider the spectral information in the collection processes. Hence, results in the CSRM runs are fairly consistent with the implications of the theoretical consideration about the role of the conversion and sedimentation in the LWP determination in thin clouds. These results are also supported by the previous study about the dependence of the response of the role to aerosols on LWP. However, the saturation adjustment scheme and the autoconversion and collection parameterizations with 
a fixed threshold and a constant collection efficiency in the GCM runs are not able to take into account the feedbacks explicitly. The results here demonstrate that the absence of the feedbacks leads to much more efficient conversion of cloud liquid to rain and much more important role of sedimentation in the cloud response to aerosols.

Next, mechanisms leading to the different increase in condensation for the GCM- and CSRM-PD runs compared to condensation in the PI runs are examined. Also, mechanisms for different condensation between the CSRM and GCM runs for each of the PI and PD conditions are examined. For the examination, the factors determining condensation are investigated.

\subsubsection{Interactions among CDNC, condensation, and dynamics}

The equation for the change in mass of droplets from vapor diffusion integrated over the size distribution in the CSRM runs is Eq. (2) in Lee et al. (2009a).

Among the variables associated with the condensational growth of droplets in the diffusion equation, differences in the supersaturation and CDNC contribute most to the differences in condensation between the CSRM-PD run and the CSRM-PI run. Percentage differences in the other variables are found to be $\sim$ two orders of magnitude smaller than those in supersaturation and CDNC throughout the simulation period. Figure 10a shows the time series of CDNC and Fig. 10b shows the time series of supersaturation when the stratocumulus clouds dominate in both of the simulations. CDNC and supersaturation are conditionally averaged over areas where the condensation rate $>0$. The conditional average is the arithmetic mean of the variable over the grid points where the condensation rate $>0$ (grid points with no condensation are excluded from the average). Figure 10a and 10 indicate that supersaturation is generally larger in the CSRM-PI run than in the CSRM-PD run. However, the condensation rate is generally higher, leading to larger cumulative condensation in the CSRM-PD run than in the CSRM-PI run (during the time when stratocumulus clouds dominate) (Table 3). This is ascribed to the larger CDNC (as shown in Fig. 10a) which provides a larger surface area for water-vapor condensation in the CSRM-PD run compared to that in the CSRM-PI run. The larger CDNC is mainly due to the increased aerosols in the CSRM-PD run. The effects of the CDNC increase on the surface area of droplets and thus on condensation compete with the effects of the supersaturation decrease on the condensation. The effects of the increased surface area for condensation outweigh the effects of decreased supersaturation. This leads to an increase in the condensation in the CSRM-PD run. This results in the larger averaged LWP over the period prior to 00:00 LST on 17 July in the CSRM-PD run compared to that in the CSRM-PI run.

Increased condensation provides more condensational heating, and, thereby, intensifies updrafts as shown in Fig-
16 LST June 30th - 00 LST July 17th
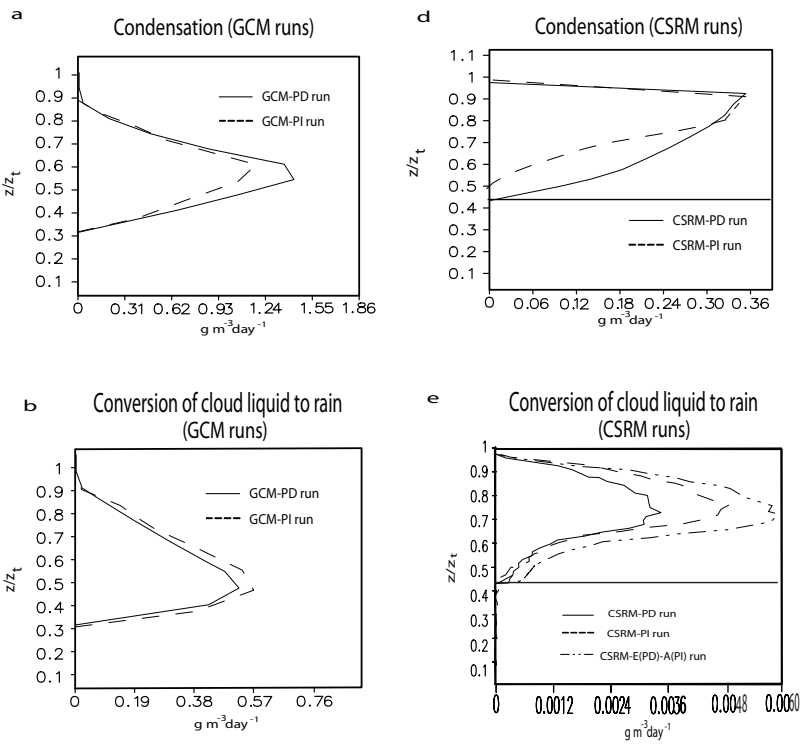

c Sedimentation-induced liquid mass change

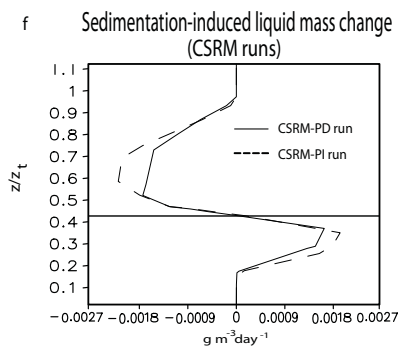

Fig. 9. Vertical distribution of time- and area-averaged (a) and (d) condensation for the GCM runs and the CSRM runs, respectively, (b) and (e) conversion of cloud liquid to rain for the GCM runs and the CSRM runs, respectively, and (c) and (f) sedimentationinduced liquid mass change for the GCM runs and the CSRM runs, respectively, in $\mathrm{g} \mathrm{m}^{-3} \mathrm{day}^{-1}$ over the period before 00:00 LST on 17 July when stratocumulus clouds dominate for the CSRM and GCM runs. The solid horizontal line in (d), (e), and (f) is the average cloud-base height normalized with respect to cloud-top height $\left(z_{t}\right)$.

ure 11a. The variance of the other experiments in Fig. 11a will be discussed in the following sections. The increased updrafts in turn increase condensation. This establishes a positive feedback between updrafts and condensation which plays a crucial role in the increased LWP in the CSRM-PD run. Note that increased condensation not only increases LWC but also increases evaporation, and, thus, entrainment. Increased cloud liquid due to the increased condensation increases cloud liquid detrained into unsaturated areas and this leads to enhanced evaporation and, thereby, entrainment. The effects of condensation on LWC outweigh those of evaporation and entrainment, leading to the increased LWP in the $\mathrm{PD}$ run. Hence, the interactions among CDNC, condensation, and dynamics (i.e., updrafts) mostly determine the differences in condensation and thereby the LWP response between the CSRM-PI and -PD runs. 

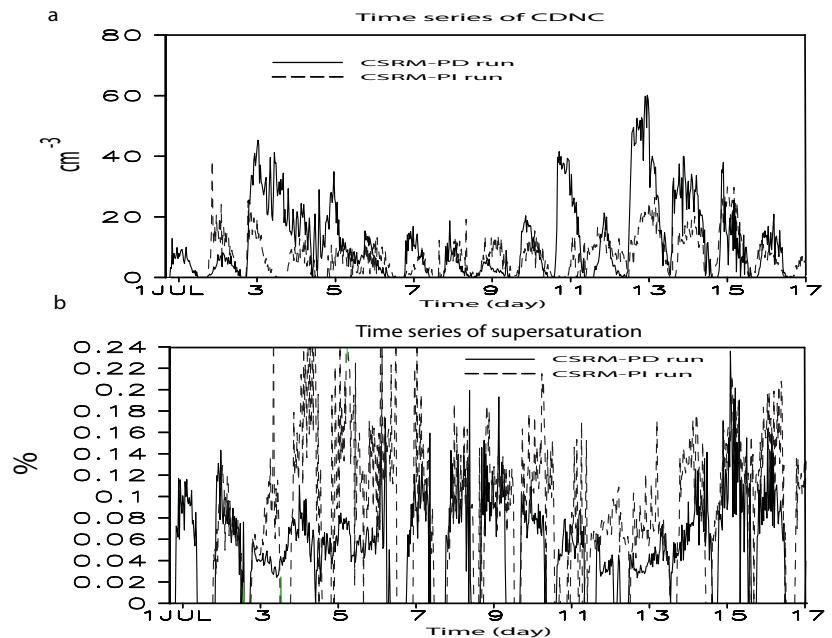

Fig. 10. Time series of conditionally averaged (a) $\mathrm{CDNC}\left(\mathrm{cm}^{-3}\right)$ and (b) supersaturation (\%) over areas where the condensation rate $>0$ for the CSRM-PD run and the CSRM-PI run.

However, unlike the CSRM, the saturation adjustment in the GCM with no consideration of the effect of varying surface area of droplets on condensation is strongly controlled by the large-scale environment. The interactions among CDNC, supersaturation and dynamics are not able to be resolved due to the use of coarse resolutions, whereas the largescale environment is resolvable in the GCM. The variation of large-scale environment is not substantial. This leads to $\sim 1.5$ times smaller percentage increase of condensation in the GCM-PD run than in the CSRM-PD run with the PI-toPD change as seen in Fig. 9a and d and Table 3. As shown in the following Sect. 6.3.4, when the effect of aerosols on condensation is excluded and only that of environment is included, the LWP variation with the PI-to-PD change decreases substantially as compared to when both effects are included even in the CSRM runs.

The consideration of the explicit feedbacks between CDNC and supersaturation tends to smooth out supersaturation. Note that these feedbacks are simulated explicitly due to the use of high resolution and the prediction of supersaturation in the CSRM runs. This leads to smaller supersaturation in the CSRM than the diagnosed supersaturation in the GCM in each of the PI run and the PD run. This leads to increased condensation in the GCM-PD (-PI) run as compared to that in the CSRM-PD (-PI) run. This increased condensation is large enough to result in a larger LWP despite the higher conversion efficiency in the GCM-PD (-PI) run than in the CSRM-PD (-PI) run during the time when stratocumulus clouds dominate. This results in a better agreement in LWP between the CSRM-PD run and the MODIS observation than between the GCM-PD run and the MODIS observation. The consideration of the explicit feedbacks between CDNC and supersaturation also lowers the sensitivity of LWP to diurnal decoupling. In other words, the LWP sensitivity to diur-

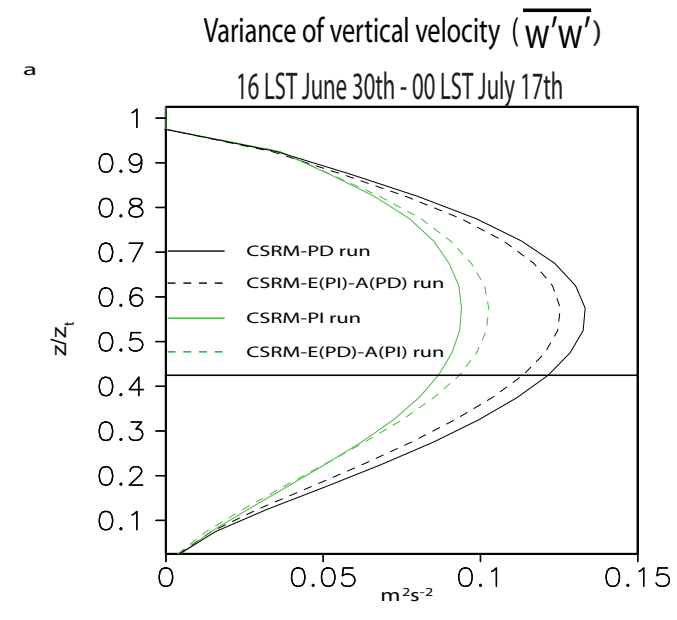

b

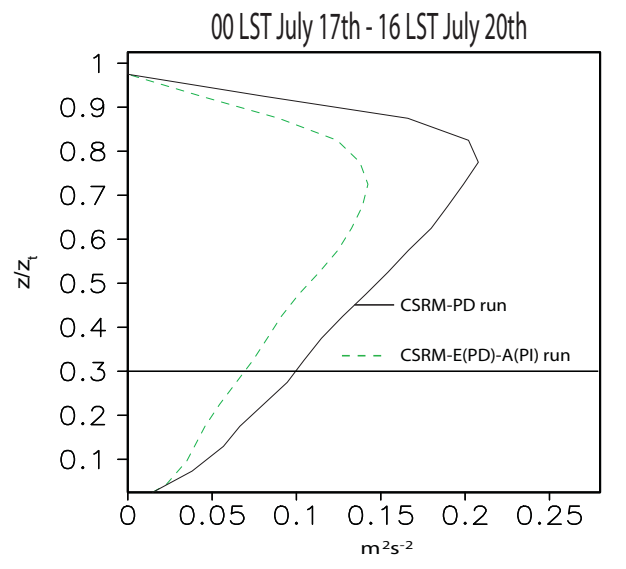

Fig. 11. Vertical distribution of the time- and area-averaged variance of vertical velocity $\left(\overline{w^{\prime} w^{\prime}}\right)\left(\mathrm{m}^{-2} \mathrm{~s}^{-2}\right)$ (a) for all of the CSRM runs and (b) for the CSRM-PD run and the CSRM-E(PD)-A(PI) run. (a) and (b) are averaged over 16:00 LST on 30 June-00:00 LST on 17 July and over 00:00 LST on 17 July-16:00 LST on 20 July, respectively. The solid horizontal line in each figure is the average cloud-base height normalized with respect to cloud-top height $\left(z_{t}\right)$.

nal variation of the transportation of water vapor from the surface to the upper layers in the CSRM runs is lowered. The presence of interactions between CDNC and supersaturation acts to damp down (or smooth out) the variation in supersaturation with varying decoupling. This leads to much larger temporal fluctuation (or diurnal variation) in LWP in the GCM runs than in the CSRM runs as shown in Fig. 7.

\subsubsection{Effects of cloud-base instability on LWP}

The surface precipitation is absent in the CSRM runs before 00:00 LST on 17 July as indicated by Fig. 9f. Hence, precipitation does not stabilize the whole MBL. It only changes the stability around cloud base and increased rain evaporation increases instability around cloud base in stratiform clouds (Jiang et al., 2002; Lee et al., 2009a and b) 
Figure 12a depicts the area-averaged rain evaporation in the CSRM-PD run and the CSRM-PI run. This figure confirms that the precipitation does not reach the surface. It also confirms that rain evaporates mostly around cloud base (at $z / z_{t} \sim 0.4$ to 0.5 where $z_{t}$ is cloud-top height) in both the CSRM-PD run and the CSRM-PI run. Figure 9e shows that more droplets are converted to rain in the CSRM-PI run. Hence, more rain falls to around the cloud base in the CSRMPI run than in the CSRM-PD run. This in turn leads to a larger evaporation of rain just below the cloud base as shown in Figure 12a. Figure 12b depicts area-averaged profile of lapse rate $\frac{d \theta}{d z}$ over 16:00 LST on 30 July-00:00 LST on 17 July. Here, $\theta$ is potential temperature. This figure indicates that the increase in evaporation below cloud base leads to a larger instability in the CSRM-PI run, since $\frac{d \theta}{d z}$ is smaller in the CSRM-PI run below cloud base. Figure $12 \mathrm{c}$ shows the domain-averaged profile of potential temperature over 16:00 LST on 30 June-00:00 LST on 17 July. Smaller $\frac{d \theta}{d z}$ below cloud base leads to lower potential temperature in the CSRM-PI run around cloud base.

The increased cloud-base instability tends to increase condensation in the CSRM-PI run by inducing an increase in the intensity of updrafts. However, with the increasing (decreasing) aerosols, interactions between CDNC, supersaturation, and dynamics and associated condensation increase (decrease) as explained in the previous section. In the CSRM runs, the effect of the decreasing interactions (among CDNC, supersaturation, and dynamics) on condensation outweighs that of the increasing cloud-base instability with decreasing aerosols in the CSRM-PI run. This explains the smaller timeand domain-averaged updrafts, condensation and thus LWP in the CSRM-PI run than in the CSRM-PD run during the time when stratocumulus clouds dominate.

Results here (shown in Sects. 6.3.1-6.3.3) indicate that microphysics parameterizations, able to predict particle mass and number, and thereby, surface area, need to be implemented into climate models. These parameterizations need to be coupled with a prediction of supersaturation. These parameterizations should also be able to take into account the interactions between rain evaporation and the cloud-base instability. This implementation can be critical for a correct simulation of the effects of aerosols on thin clouds.

\subsubsection{Effects of environmental conditions on LWP}

There are differences in both the background aerosols and environmental conditions (characterized by the initial condition, large-scale forcings, and surface fluxes) imposed on the CSRM between the CSRM-PD run and the CSRM-PI run. It is well known that environmental conditions affect aerosolcloud interactions as well as cloud development (Jiang et al., 2002; Ackerman et al., 2004; Guo et al., 2007). Hence, it is needed to examine the relative role of changes in aerosols in determining the LWP response to the PI-to-PD change in thin stratocumulus clouds (explained in the previous sec- a

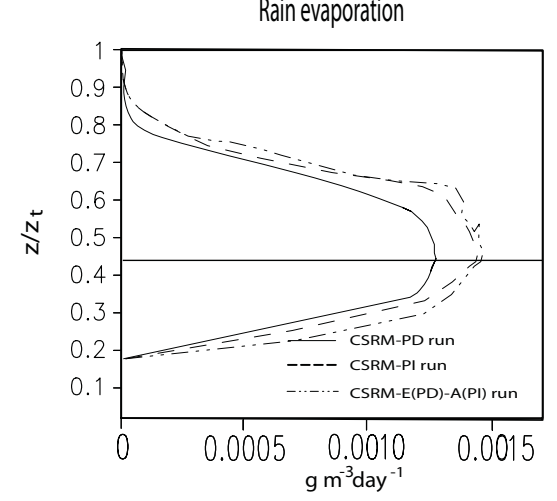

b
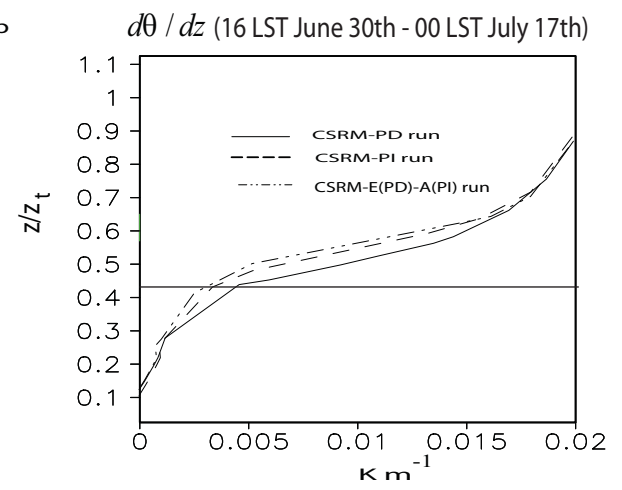

c Potential temperature (16 LST June 30 th - 00 LST July 17 th)

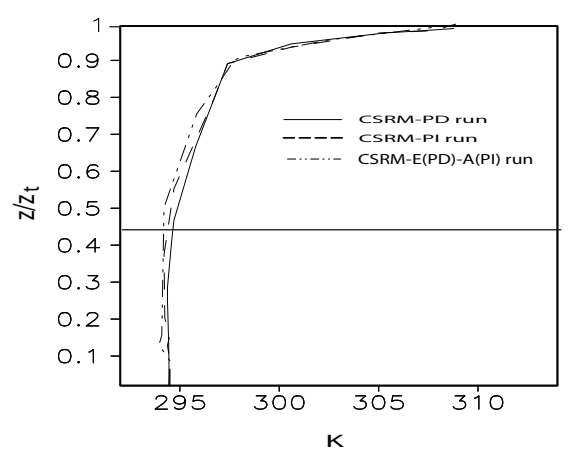

Fig. 12. Vertical distribution of time- and area-averaged (a) rain evaporation, (b) $\frac{d \theta}{d z}\left(\mathrm{~K} \mathrm{~m}^{-1}\right)$, and (c) $\theta(\mathrm{K})$ for the CSRM-PD run, the CSRM-PI run, and CSRM-E(PD)-A(PI) run. (a) is averaged over the entire simulation period while (b) and (c) are averaged over 16:00 LST on 30 June-00:00 LST on 17 July. The solid horizontal line in each figure is the average cloud-base height normalized with respect to cloud-top height $\left(z_{t}\right)$.

tions) to that of changes in environmental conditions. Two additional simulations were performed for this examination. The first (second) adopts the PD (PI) environment with the PI (PD) aerosol. Henceforth, the first and the second simulations are referred to as the CSRM-E(PD)-A(PI) run and the CSRM-E(PI)-A(PD) run, respectively (Table 1). Also, these simulations are repeated for the GCM run using a singlecolumn model setup to compare the relative role of changes 
in aerosols in the GCM runs to that in the CSRM runs. These simulations for the GCM are referred to as the GCM-E(PD)$\mathrm{A}(\mathrm{PI})$ run and the GCM-E(PI)-A(PD) run, respectively (see Table 1 for the description of these runs).

The budget terms for cloud liquid-water mass for both the CSRM-PD run and the CSRM-E(PD)-A(PI) run before 00:00 LST on 17 July (for the time period during which stratocumulus clouds dominate) is shown in Table 3. As was the case in the comparison between the CSRM-PD run and the CSRM-PI run, condensation controls the variation of the liquid-water budget between the CSRM-PD run and the CSRM-E(PD)-A(PI) run. However, the role of the conversion of liquid water to precipitation (i.e., autoconversion + accretion) in the variation is negligible. As shown in Fig. 12b, a larger cloud-base instability develops in the CSRM-E(PD)-A(PI) run than in the CSRM-PD run. No surface precipitation is simulated during the time period when stratocumulus clouds dominate in the CSRM-E(PD)-A(PI) run. The lower aerosol concentration leads to more conversion of cloud liquid to rain in the CSRM-E(PD)-A(PI) run than in the CSRM-PD run (Fig. 9e). This in turn leads to more cloud-base rain evaporation to induce a larger cloudbase instability in the CSRM-E(PD)-A(PI) run than in the CSRM-PD run (Fig. 12a and b). However, the larger instability does not lead to the larger updrafts, condensation, and LWP in the CSRM-E(PD)-A(PI) run than in the CSRM-PD run when stratocumulus clouds dominate as shown in Figure 11a and Tables 2 and 3. This can also be seen in the upper horizontal arrow in Fig. 8b. It depicts increasing LWP with the PI-to-PD change in aerosols at the PD environment. The effects of the increased aerosols on CDNC and thus condensation outweigh the effects of the increased cloud-base instability. This is also shown in the comparison between the CSRM-PD run and the CSRM-PI run. Hence, the mechanisms elaborated in the previous sections leading to larger LWP in the CSRM-PD run (when stratocumulus clouds are dominant) are operative with the change in aerosols regardless of whether the change in the environmental conditions occurs. This is supported by the comparison between the CSRM-PI run and the CSRM-E(PI)-A(PD) run for the period before 00:00 LST on 17 July. The CSRM-E(PI)-A(PD) run with higher aerosols than those in the CSRM-PI run has higher condensation (controlling the liquid-mass and thus LWP responses to aerosols). This leads to larger updrafts, LWC, and thus LWP in the CSRM-E(PI)-A(PD) run (Fig. 11a, Tables 2 and 3). This can also be seen in lower horizontal arrow in Fig. 8b. It depicts increasing LWP with the PI-to-PD change in aerosols at the PI environment. The larger averaged updrafts in the CSRM-E(PI)-A(PD) run than in the CSRM-PI run shown in Fig. 11a also holds over the entire simulation period. The increased condensation and LWP in the CSRM-E(PI)-A(PD) run is despite the lower cloudbase instability in the CSRM-E(PI)-A(PD) run than that in the CSRM-PI run. Due to the increased surface areas of droplets, condensation increases in the CSRM-E(PI)-A(PD).
The LWP variations due to the change from the PI environmental condition to the PD environmental condition for both the PI aerosol and the PD aerosol is one to two orders of magnitude smaller than the LWP variation shown between the CSRM-PD run and the CSRM-PI run before 00:00 LST on 17 July (Table 2). This can be seen in the LWPs in Table 2 for the CSRM-PI (the CSRM-PD) run and the CSRM$\mathrm{E}(\mathrm{PD})-\mathrm{A}(\mathrm{PI})$ (the CSRM-E(PI)-A(PD)) run compared to that between the CSRM-PI run and the CSRM-PD run for the PI (PD) aerosol. This can also be seen in the comparison of a diagonal arrow to a vertical arrow either at the PD aerosol (the right vertical arrow) or at the PI aerosol (the left vertical arrow) for the CSRM runs in Fig. 8b. However, for the PI environment and the PD environment, changes in the aerosol from the PI level to the PD level account for more than $\sim 95 \%$ of the LWP variation shown between the CSRMPI and the CSRM-PD runs (for the time when stratocumulus clouds dominate). This can be seen in the LWP variation in Table 2 between the CSRM-PI (the CSRM-PD) run and the CSRM-E(PI)-A(PD) (the CSRM-E(PD)-A(PI)) run compared to that between the CSRM-PI run and the CSRM-PD run for the PI (PD) environment. This can also be seen in the comparison of a diagonal arrow to a horizontal arrow either at the PD environment (the upper horizontal arrow) or at the PI environment (the lower horizontal arrow) for the CSRM runs in Fig. 8b. Aerosol changes play a much more important role in the LWP changes (associated with the PI-to-PD transition) than the changes in the environment for stratocumulus clouds.

In contrast, the single-column simulations show that LWP variations due to the PI-to-PD change in environment for both the PI aerosol and the PD aerosol are larger than those due to the PI-to-PD change in aerosols for both the PI environment and the PD environment in the GCM runs (Table 2 and Fig. 8b). This is due to the strong sensitivity of saturation adjustment scheme (leading to the strong sensitivity of condensation) in the GCM to the environmental conditions (Table 3). However, conversion of cloud liquid to rain in the GCM runs is found to be much more strongly sensitive to the PI-to-PD change in aerosols than to that in environment (Table 3). The single-column simulations show that the changes in condensation with changing environment accounts for the LWP variation between the GCM-PD and GCM-PI runs $\sim 2$ times larger than those in conversion with changing aerosols (Table 3 and Fig. 8b).

Also, it should be pointed out that there is an increase in condensation and thus LWP due to the change from the PI environmental condition to the PD environmental condition for each of the PI and the PD aerosols when stratocumulus clouds dominate. However, the increase is negligibly small (Tables 2 and 3). This can be seen in a vertical arrow showing increasing LWP with the PI-to-PD change in the environment either at the PD aerosol (the right arrow) or at the PI aerosol (the left arrow) for the CSRM run in Fig. 8b. This increase is associated with the surface LH flux. The LH flux 
is generally larger in the PD environment than in the PI environment (Fig. 3). As Guo et al. (2007) showed, the increase in the surface LH flux leads to increases in the LWP of stratocumulus clouds. The larger surface LH fluxes induce larger buoyancy fluxes. This in turn induces a larger intensity of vertical velocity. The larger intensity of vertical velocity leads to larger condensation and LWP in thin stratocumulus clouds in the PD environment compared to the PI environment for the given aerosols (Figs. $8 \mathrm{~b}$ and 11a and Tables 2 and 3). Also, as can be seen in Fig. 2, there is a larger large-scale advection of humidity and temperature in the PD environment in the MBL (generally below $\sim 1 \mathrm{~km}$ for stratiform clouds as indicated by Fig. 6). This also contributes to an increase in condensation and LWP by increasing the vertical velocity in the cloud layer in the PD environment.

The larger large-scale subsidence in the PD environment than in the PI environment leads to lower cloud-top height in the CSRM-PD and CSRM-E(PD)-A(PI) runs than in the CSRM-PI run during the period between the beginning of the simulation and 00:00 LST on 13 July as shown in Fig. 6a, 6c, and e. Figure 6e depicts the time-height cross section of cloud-liquid mixing ratio for the CSRM-E(PD)-A(PI) run. The averaged large-scale subsidence over this period is 0.5 and $0.3 \mathrm{~cm} \mathrm{~s}^{-1}$ in the PD and PI environment, respectively. During the period between 00:00 LST on 13 July and 00:00 LST on 17 July, the increase in the surface LH fluxes starting around 00:00 LST on 13 July (Fig. 3) increases entrainment through the MBL top and, thus, leads to the higher cloud top in the CSRM-PD and CSRM-E(PD)-A(PI) runs than in the CSRM-PI run.

\subsection{Transition from stratocumulus to cumulus}

\subsubsection{LH-flux induced formation of cumulus clouds}

The time- and domain-averaged LWP over the entire simulation period in the CSRM-PD (GCM-PD) run is larger than that in the CSRM-PI (GCM-PI) run. The increase in the LWP in the CSRM-PD run (as compared to the LWP in the CSRMPI run) is larger than that in the GCM-PD run (as compared to the LWP in the GCM-PI run). This is due to a substantial increase in cloud-liquid mixing ratio after around 00:00 LST on 17 July in the CSRM-PD run. This increase is caused by the transition of the cloud type from the stratocumulus clouds to the cumulus clouds. The increase in the surface LH fluxes starting around 00:00 LST on 13 July (Fig. 3) induces the transition (see Sect. 6.3 in Lee et al. (2009a) for details on the role of the surface LH fluxes in the transition to cumulus clouds). This makes LWP in the CSRM-PD run much larger than that in the CSRM-PI run after 00:00 LST on 17 July (Fig. 7 and Table 2). This is also shown in the diagonal arrow for the CSRM run in Fig. 8c for the period after 00:00 LST on 17 July. However, the LWP in the GCM-PD run is smaller than that in the GCM-PI run after 00:00 LST on 17 July (see the diagonal arrow for the GCM run in Fig. 8c and Table 2). This is partly due to the lack of any development of cumulus clouds in the set of GCM runs after around 00:00 LST on 17 July (Fig. 7).

The absence of cumulus clouds in the GCM-PD run is associated with coarse resolutions in the GCM used here. The coarse resolution prevents the explicit interactions between the surface LH fluxes and in-cloud buoyancy fluxes (essential for the formation of cumulus clouds) described in Lee et al. (2009a). In the GCM, instead of resolving these interactions, cumulus clouds are parameterized by Hack's (1994) scheme (due to the use of the coarse resolutions). Hack's scheme can be triggered when the large-scale moist instability (controlled by large-scale forcings) exists. However, in the region of interest here (in the MBL), there is no largescale instability developing throughout the simulation period. Hence, Hack's scheme is not activated and thus cumulus clouds are not formed in the GCM.

\subsubsection{Role of aerosols in the formation and development of cumulus clouds}

In this section, the role of aerosols in the formation and development of cumulus clouds is examined and compared to that of the surface LH fluxes. Since aerosols are known to change the LH distribution, precipitation, and thus instability in MBL (Stevens et al., 1998), they can play a role in the transition to cumulus clouds.

Due to the increase in the surface LH flux starting around 00:00 LST on 13 July in the PD environment, cumulus clouds start to develop in the CSRM-E(PD)-A(PI) run as in the CSRM-PD run around 00:00 LST on 17 July as shown in Fig. 6e. This leads to a large increase in the averaged LWP after 00:00 LST on 17 July as shown in Table 2. However, no cumulus clouds are simulated in the CSRM-E(PI)-A(PD) run where the LH flux increase is not as significant as in the CSRM-E(PD)-A(PI) run. Both the CSRM-E(PD)-A(PI) run and the CSRM-PD run show the formation of cumulus clouds and cumulus clouds are absent in the CSRM-E(PI)-A(PD) run. Thus, we infer that the dependence of the cumulus formation on the aerosol level is very weak and the magnitude of the increase in the surface LH flux controls this formation.

Also, it needs to be pointed out that the averaged LWP in the CSRM-E(PD)-A(PI) over the period after 00:00 LST on 17 July is $40 \%$ smaller than that in the CSRM-PD run as shown in Table 2. This is shown in the upper horizontal arrow (indicating the increasing cumulus mass with the change in aerosols from the PI to PD level at the PD environment) in Fig. 8c. This indicates that although the formation of cumulus clouds is basically determined by how large the LH flux increases, the mass of cumulus clouds is controlled by the aerosol level. Sensitivity tests show that this effect of aerosols on cumulus clouds is robust to differences in environmental conditions on 00:00 LST on 17 July (acting as initial conditions for cumulus clouds) between the CSRM$\mathrm{PD}$ and CSRM-E(PD)-A(PI) runs. Figure $11 \mathrm{~b}$ shows that the 
variance of the vertical velocity is larger in the CSRM-PD run than in the CSRM-E(PD)-A(PI) run (after 00:00 LST on 17 July). This leads to larger condensation and liquid mass after 00:00 LST on 17 July. This indicates that the interactions among the LH flux, the buoyancy flux, and dynamics in cumulus clouds become stronger with increasing aerosols. These stronger interactions with increasing aerosols lead to a larger increase in the averaged LWP over the entire simulation period in the CSRM-PD run relative to the CSRM$\mathrm{E}(\mathrm{PI})-\mathrm{A}(\mathrm{PD})$ run than in the CSRM-E(PD)-A(PI) run relative to the CSRM-PI run as shown in Table 2. This is also shown in the comparison between the two vertical arrows in Fig. 8a. They depict the increasing LWP with the PI-to-PD change in the environment at the PI (the left arrow) and the PD (the right arrow) aerosols. The sensitivity of the response of the formation and development of cumulus clouds and thus the averaged LWP over the entire period to the changes in the environment (more specifically, changes in the surface LH fluxes) increases with increasing aerosols.

\subsection{Dependence of the LWP responses to aerosols on cloud type}

It is notable that there are larger increases in the averaged LWP over the period involving cumulus clouds with the change from the PI aerosols to the PD aerosols than in the period when stratocumulus clouds are dominant (i.e., comparing the CSRM-PD run and the CSRM-E(PD)-A(PI) run). This is shown in the comparison between the upper horizontal arrows in Fig. 8b and in Fig. 8c. The upper horizontal arrow in Fig. 8c shows larger LWP variation than that in Fig. 8b. Figure $8 \mathrm{c}$ and $\mathrm{b}$ are for the period when cumulus clouds form and for the period when stratocumulus clouds dominate, respectively. These increases in the period with cumulus clouds are also larger than those between the CSRM-PI run and the CSRM-E(PI)-A(PD) run when stratocumulus clouds dominate either before or after 00:00 LST on 17 July (see Table 2). This can be seen in the comparison of the lower horizontal arrow in each of Fig. $8 \mathrm{~b}$ and $\mathrm{c}$ to the upper arrow in Fig. 8c. Note that stratiform clouds dominate for the entire simulation period with the PI environment. These larger increases indicate that liquid mass changes due to aerosols depend on the cloud type. Aerosol effects on cumulus clouds induce larger changes in liquid mass than those on stratiform clouds.

\section{Summary and discussion}

A 20-day simulation was performed using a CSRM coupled with a double-moment microphysics for a case of thin stratocumulus clouds for each of the PD condition (the CSRMPD run) and PI condition (the CSRM-PI run). These clouds are located at $\left(30^{\circ} \mathrm{N}, 120^{\circ} \mathrm{W}\right)$ off the coast of the western Mexico. Initial conditions, large-scale forcings, surface fluxes, and aerosols produced by a GCM simulation with the PD (PI) conditions (the GCM-PD (PI) run) at $\left(30^{\circ} \mathrm{N}\right.$, $120^{\circ} \mathrm{W}$ ) were imposed on the CSRM-PD (PI) run. This enabled a comparison of the responses of thin clouds to the transition from the PI condition to the PD condition simulated in a GCM to those in the CSRM. The much higher resolution and more detailed representation of cloud microphysics were used for the CSRM as compared to those in the GCM. This enables the CSRM to act as a benchmark to assess these responses simulated by the GCM.

The coarse spatial resolution (a main cause of the first line of complication discussed in Zhang et al., 2003) employed in climate models is not able to resolve the effect of aerosols on interactions between supersaturation and the surface area of cloud droplets in the cloud layer. Instability around cloud base is not resolved by the coarse resolution as well. These interactions and instability play important roles in aerosol effects on LWP in thin stratocumulus clouds simulated by the CSRM here. So far, in general, parameterizations for the representation of the LWP variation with aerosols have simply relied on the aerosol-induced changes in the autoconversion of cloud liquid and hydrometeor sedimentation in climate models. They do not take into account feedbacks among microphysics, dynamics, and the instability which are affected by aerosols.

In addition, this study indicates that the second line of complication of Zhang et al. (2003) can also cause a high uncertainty in the simulation of changing cloud properties since industrialization. Most of GCMs (including the GCM used here) and some of CSRMs have adopted saturation adjustment schemes. These schemes are not able to predict supersaturation and thereby to consider the effects of interactions between supersaturation and the surface area of cloud droplets (varying with aerosols) on condensation. This implies that although the first line of complication were removed by using high resolutions, the effect of aerosols on these interactions would not be simulated when the saturation adjustment is used in climate models. When the stratocumulus clouds dominate, the increase in the LWP between the PD and PI runs was controlled by the increase in condensation in the CSRM runs. However, the role of the decrease in the conversion of cloud liquid to rain in this LWP variation between the PD and PI runs was negligible in the CSRM runs. This is associated with the spectral information of the size distribution for collections considered in the CSRM runs. In contrast, in the GCM runs with no consideration of the spectral information, the decrease in the conversion of cloud liquid to rain played a role that was as important as that of the increase in condensation with the PI-to-PD change. This contributed to the large differences in the response of the LWP and model-top SCF to the change from the PI condition to the PD condition between the GCM and the CSRM simulations. Especially, the percentage variation of model-top SCF (which is one of the most important estimates of aerosol indirect effect) with the PI-to-PD change is much smaller in the GCM simulations than in the CSRM simulations. 
The first and second lines of complications also led to substantial discrepancies between the CSRM and the GCM for both PI and PD conditions. Supersaturation produced by updrafts is consumed by the condensation of water vapor onto droplets and increasing (decreasing) CDNC provides increasing (decreasing) surface areas of droplets for condensation. This leads to decreasing (increasing) equilibrium supersaturation, for a given background aerosol level. These interactions are explicitly simulated in the CSRM runs due to the use of the high resolution and the prediction of supersaturation. However, condensation is diagnosed based on environmental conditions in the GCM runs. It is found that the explicit simulation of these interactions tends to produce less condensation in the CSRM run as compared to the saturation adjustment scheme in the GCM run. This is for the stratocumulus regime in both the PD and the PI runs. Also, these interactions lead to the smaller LWP being closer to the MODIS-observed LWP in the CSRM-run than in the GCMrun in the stratocumulus regime. Hence, for these aerosol and environmental conditions, climate models with the saturation adjustment are likely to overestimate the mass of stratocumulus clouds.

This study indicates that the first line of complication in the parameterization of clouds in GCMs (discussed in Zhang et al., 2003) can affect the simulation of cloud types. The subgrid-scale interactions among the increasing surface $\mathrm{LH}$ fluxes, buoyancy fluxes, and entrainment explicitly simulated in the CSRM enabled the development of cumulus clouds with the PD condition. However, the absence of the explicit simulation of these interactions due to the coarse resolution prevented the formation of cumulus clouds in the GCM. The development of cumulus clouds in the CSRM led to substantial differences between the GCM and CSRM in the response of the LWP and thus radiation to the change from PI to PD conditions. This development of cumulus clouds with increasing LH fluxes implies that the climate change associated with the increasing greenhouse gases and thus the surface temperature can act in favor of increasing the frequency of the stratocumulus-to-cumulus transition. This is because increases in temperature near the Earth's surface due to increases in greenhouse gases can increase the surface LH fluxes as shown by Bretherton and Wyant (1997). They showed that the surface LH fluxes increase with the increasing sea surface temperatures. This increase in the LH fluxes induced by the increasing greenhouse gases may have impacts on the transition of stratocumulus clouds to cumulus clouds and thus on the mass of warm clouds. This in turn may affect the effects of warm clouds on the global radiation budget. It should be pointed out that supplementary simulations indicated that the increase of aerosols since industrialization can increase the sensitivity of the stratocumulus-to-cumulus transition and the associated changes in the mass of warm clouds to increasing LH fluxes (associated with the greenhouse gases). Also, supplementary simulations demonstrated that aerosol effects on clouds depend on the cloud type. The mass of water in cumulus clouds is more sensitive to aerosols than the mass of water in stratocumulus clouds. Hence, the more frequent development of warm cumulus clouds due to increasing LH fluxes (associated with the increasing greenhouse gases) is likely to increase the sensitivity of the mass of warm clouds to aerosols. The GCM is expected to be unable to take into account the changing radiation budget due to possible changes in cloud types, the role of aerosols in these changes, and the changing cloud sensitivity to aerosols. This is because these are associated with sub-grid interactions among the surface LH fluxes, buoyancy fluxes, and entrainment.

Stevens et al. (2005) indicated that the 20-m vertical resolution adopted in the CSRM runs could not be fine enough to simulate stratocumulus clouds with confidence. However, Guo et al. (2008) found that basic features of the integrations (e.g., the inversion height, LWP and cloud-top radiative cooling) were similar for vertical resolutions of $40 \mathrm{~m}$ or finer. An additional set of simulations with a vertical resolution of $5 \mathrm{~m}$ for the CSRM-PD and -PI runs (only for the period when stratocumulus clouds are dominant cloud type for both runs) is performed. Consistent with the finding of Guo et al. (2008), these simulations show nearly identical results (e.g., LWP, effective radius, and cloud fraction) to those with the resolution of $20 \mathrm{~m}$ below the top of the MBL. This indicates that the qualitative nature of results here can be considered robust to the vertical resolution.

The generalization of the results reported here requires further investigation. For different changes in environment and aerosols than here, the LWP response and the associated roles of the environment in the change from the PI to PD will be different than shown here. More case studies of thin stratiform clouds experiencing the various PI-to-PD changes are needed in order to establish a generalization of the results reported here.

Acknowledgements. The authors wish to thank Derek Posselt and Minghuai Wang for providing the GCE coupled with doublemoment microphysics and the GCM data used here and valuable discussions. We also thank anonymous reviewers for their valuable comments to enhance the quality of this paper. This paper was prepared under US Department of Energy ARM program (DE FG02 97 ER62370).

Edited by: J. Quaas

\section{References}

Ackerman, A. S., Kirkpatrick, M. P., Stevens, D. E., and Toon, O. B.: The impact of humidity above stratiform clouds on indirect aerosol climate forcing, Nature, 432, 1014-1017, 2004.

Andres, R. J. and Kasgnoc, A. D.: A time-averaged inventory of subaerial volcanic sulfur emissions, J. Geophys. Res., 103, 25251-25261, 1998. 
Abdul-Razzak, H. and Ghan, S. J.: A parameterization of aerosol activation 2. Multiple aerosol types, J. Geophys. Res., 105, 6837-6844, 2000.

Abdul-Razzak, H. and Ghan, S. J.: A parameterization of aerosol activation - 3. Sectional representation, J. Geophys. Res., 107, 4026, doi:10.1029/2001JD000483, 2002.

Albrecht, B. A.: Aerosols, cloud microphysics, and fractional cloudiness, Science, 245, 1227-1230, 1989.

Beheng, K. D.: A parameterization of warm cloud microphysical conversion processes, Atmos. Res., 33, 193-206, 1994.

Bluestein, H. B.: Synoptic-Dynamic Meteorology in Midlatitudes: Volume II: Observations and Theory of Weather Systems (Synoptic-Dynamic Meteorology in Midlatitudes), Oxford University Press, UK, 594 pp., 1993.

Boville, B. A., Rasch, P. J., Hack, J. J., and McCaa, J. R.: Representation of clouds and precipitation processes in the community atmosphere model version 3 (cam3), J. Climate, 19, 2184-2198, 2006.

Boucher, O., Treut, H. L., and Baker, M. B.: Precipitation and radiation modeling in a general circulation model: Introduction of cloud microphysical process. J. Geophys. Res., D100, 1639516414, 1995.

Bretherton, C. S. and Wyant, M. C.: Moisture transport, lowertropospheric stability, and decoupling of cloud-topped boundary layers, J. Atmos. Sci., 54, 148-167, 1997.

Chuang, C. C., Penner, J. E., Taylor, K. E., Grossman, A. S., and Walton, J. J.: An assessment of the radiative effects of anthropogenic sulfate, J. Geophys. Res., 102, 3761-3778, 1997.

Collins, W. D., Rasch, P. J., Boville, B. A., Hack, J. J., McCaa, J. R., Williamson, D. L., Briegleb, B. P., Bitz, C. M., Lin, S. J., and Zhang, M. H.: The formulation and atmospheric simulation of the community atmosphere model version 3 (cam3), J. Climate, 19, 2144-2161, 2006.

Cotton, W. R., Stephens, M. A., Nehrkorn, T., and Tripoli, G. J.: The Colorado State University three-dimensional cloud/mesoscale model. Part II: An ice phase parameterization, J. Rech. Atmos. 16, 295-319, 1982.

Cubasch, U., Dai, X., Ding, Y., et al.: Climate change 2001: The scientific basis, in Contribution of Working Group I to the Third Assessment Report of the Intergovernmental Panel on Climate Change, Cambridge Univ. Press, New York, 528-582, 2001.

Feingold, G., Tzivion, S., and Levin, Z.: Evolution of raindrop spectra. Part I: Solution to the stochastic collection/breakup equation using the method of moments, J. Atmos. Sci., 45, 3387-3399, 1988.

Forster, P., Ramaswamy, V., Artaxo, P., et al.: Changes in atmospheric constituents and in radiative forcing, in: Climate change 2007: the physical science basis, Contribution of working group I to the Fourth Assessment Report of the Intergovernmental Panel on Climate Change, edited by Solomon, S., Qin, D., Manning, M., et al., Cambridge Univ. Press, New York, 2007.

Ginoux, P., Chin, M., Tegen, I., Prospero, J. M., Holben, B., Dubovik, O., and Lin, S. J.: Sources and distributions of dust aerosols simulated with the gocart model, J. Geophys. Res., 106, 20255-20273, 2001.

Gong, S. L., Barrie, L. A., and Blanchet, J. P.: Modeling sea-salt aerosols in the atmosphere .1. Model development, J. Geophys. Res., 102, 3805-3818, 1997.

Guo, H., Liu, Y., Daum, P. H., Zeng, X., Li, X., and Tao, W.-K.:
Effects of model resolution on entrainment (inversion heights), cloud-radiation interactions, and cloud radiative forcing, Atmos. Chem. Phys. Discuss., 8, 20399-20425, doi:10.5194/acpd-820399-2008, 2008.

Guo, H., Penner, J. E., Herzog, M., and Xie, S.: Investigation of the first and second aerosol indirect effects using data from the May 2003 Intensive Operational Period at the Southern Great Plains, J. Geophys. Res., 112, D15206, doi:10.1029/2006JD007173, 2007.

Hack, J. J.: Parameterization of moist convection in the NCAR Community Climate Model (CCM2), J. Geophys. Res., 99, 5551-5568, 1994.

Ito, A. and Penner, J. E.: Historical emissions of carbonaceous aerosols from biomass and fossil fuel burning for the period 1870-2000, Global Biogeochem. Cy., 19, GB2028, doi:10.1029/2004GB002374, 2005.

Jiang, H., Feingold, G., and Cotton, W. R.: Simulations of aerosol-cloud-dynamical feedbacks resulting from entrainment of aerosol into the marine boundary layer during the Atlantic Stratocumulus Transition Experiment, J. Geophys. Res., 107, 4813, doi:10.1029/2001JD001502, 2002.

Kettle, A. J. and Andreae, M. O.: Flux of dimethylsulfide from the oceans: A comparison of updated data seas and flux models, J. Geophys. Res., 105, 26793-26808, 2000.

Khairoutdinov, M. and Kogan, Y.: A new cloud physics parameterization in a large-eddy simulation model of marine stratocumulus, Mon. Weather Rev., 128, 229-243, 2000.

Lee, S. S., Penner, J. E., and Wang, M.: Comparison of a globalclimate model simulation to a cloud-system resolving model simulation for long-term thin stratocumulus clouds, Atmos. Chem. Phys., 9, 6497-6520, doi:10.5194/acp-9-6497-2009, 2009a.

Lee, S. S, Penner, J. E., and Saleeby, S. M.: Aerosol effects on liquid-water path of thin stratocumulus clouds, J. Geophys. Res., 114, D07204, doi:10.1029/2008JD010513, 2009 b.

Liu, X. H., Penner, J. E., and Herzog, M.: Global modeling of aerosol dynamics: Model description, evaluation, and interactions between sulfate and nonsulfate aerosols, J. Geophys. Res., 110, D18206, doi:10.1029/2004JD005674, 2005.

Liu, X., Penner, J. E., and Wang, M.: Influence of anthropogenic sulfate and black carbon on upper tropospheric clouds in the NCAR CAM3 model coupled to the IMPACT global aerosol model, J. Geophys. Res., 114, D03204, doi:10.1029/2008JD010492, 2009.

Marchand, R., Ackerman, T., Westwater, E. R., Clough, S. A., Cady-Pereira, K., and J. C. Liljegren, J. C.:An assessment of microwave absorption models and retrievals of cloud liquid water using clear-sky data. J. Geophys. Res., 108, 4773, doi:10.1029/2003JD003843, 2003.

McFarlane, S. A. and Evans, K. F.: Clouds and shortwave fluxes at Nauru. Part I: Retrieved cloud properties, J. Atmos. Sci., 61, 733-744, 2004.

Penner, J. E., Andreae, M., Annegarn, et al.: Aerosols, their direct and indirect effects, in Climate Change 2001: The Scientific Basis: Contribution of Working Group I to the Third Assessment Report of the Intergovernmental Panel on Climate Change, edited by: Houghton, J. T., Ding, Y., Griggs, D. J., et al., chap. 5, 291-336, Cambridge Univ. Press, New York, 2001.

Pruppacher, H. R. and Klett, J. D.: Microphysics of Clouds and Precipitation, 714 pp., D. Reidel, 1978. 
Ramaswamy, V., Boucher, O., Haigh, J., et al.: Radiative forcing of climate change, in Climate Change 2001: The Scientific Basis, edited by: Houghton, J. T., Ding, Y., Griggs, D. J., et al., 349416, Cambridge Univ. Press, New York, 2001.

Rasch, P. J. and Kristjánsson, J. E.: A comparison of the CCM3 model climate using diagnosed and predicted condensate parameterizations, J. Climate, 11, 1587-1614, 1998.

Rogers, R. R. and Yau, M. K.: A short course in cloud physics, Pergamon Press, 293 pp., 1991.

Rossow, W. B. and Schiffer, R. A.: Advances in understanding clouds from ISCCP, B. Am. Meteor.Soc., 80, 2261-2287, 1999.

Saleeby, S. M. and Cotton, W. R.: A large-droplet mode and prognostic number concentration of cloud droplets in the Colorado state university regional atmospheric modeling system (RAMS). Part I: Module description and supercell test simulations, J. Appl. Meteor., 43, 182-195, 2004.

Shupe, M. D. and Intrieri, J. M.: Cloud radiative forcing of the Arctic surface: The influence of cloud properties, surface albedo, and solar zenith angle, J. Climate, 17, 616-628, 2004.

Simpson, J. and Tao, W.-K.: The Goddard Cumulus Ensemble model. Part II: Applications for studying cloud precipitating processes and for NASA TRMM, Terr. Atmos. Ocean. Sci., 4, 73116, 1993

Smith, S. J., Pitcher, H., and Wigley, T. M. L.: Global and regional anthropogenic sulfur dioxide emissions, Global Planet. Change, 29, 99-119, 2001.

Smith, S., Andres, R., Conception, L., and Lurz, J.: Historical sulfur dioxide emissions 1850-2000: Methods and resutls, jgcri research report pnnl 14537, Paciific Northwest National Laboratory, Richland, WA, USA, 14537, 16, 2004.

Stevens, B., Cotton, W. R., Feingold G., and Moeng, C.H.: Large-eddy simulations of strongly precipitating, shallow stratocumulus-topped boundary layers, J. Atmos. Sci., 55, 36163638, 1998.
Stevens, B., Moeng, C. H., Ackerman, A. S., Bretherton, C. S., Chlond, A., de Roode, S., Edwards, J., Golaz, J. C., Jiang, H., Khairoutdinov, M., Kirkpatrick, M. P., Lewellen, D. C., Lock, A., Müller, F., Stevens, D. E., Whelan, E., and Zhu, P.: Evaluation of Large-Eddy Simulations via Observations of Nocturnal Marine Stratocumulus, Mon. Weather Rev., 133, 1443-1462, 2005.

Tao, W.-K, Simpson, J., Baker, D., et al.:Microphysics, radiation and surface processes in the Goddard Cumulus Ensemble (GCE) model, Meteor. Atmos. Phys., 82, 97-137,2003.

Tao, W.-K. and Simpson, J.: The Goddard Cumulus Ensemble model. Part I: Model description, Terr. Atmos. Ocean. Sci., 4, 19-54, 1993.

Tripoli, G. J. and Cotton, W. R.: A numerical investigation of several factors contributing to the observed variable intensity of deep convection over South Florida, J. Appl. Meteor., 19, 1037-1063, 1980.

Turner, D. D., Vogelmann, A. M., Austin, R. T., et al.: Thin liquid water clouds: Their importance and our challenge, B. Am. Meteor. Soc., 88, 177-190, 2007.

Wang, M., Penner, J. E., and Liu, X.: The coupled IMPACT aerosol and NCAR CAM3 climate model: evaluation of predicted aerosol number and size distribution, J. Geophys. Res., 114, D06302, doi:10.1029/2008JD010459, 2009.

Wang, M. and Penner, J. E.: Aerosol indirect forcing in a global model with particle nucleation, Atmos. Chem. Phys., 9, 239-260, doi:10.5194/acp-9-239-2009, 2009.

Weisman, M. L. and Klemp, J. B.: The dependence of numerically simulated convective storms on vertical wind shear and buoyancy, Mon. Weather Rev., 110, 504-520, 1982.

Zhang, M., Lin, W., Bretherton, C. S., Hack, J. J., and Phillip, J. R.: A modified formulation of fractional stratiform condensation rate in the NCAR Community Atmospheric Model (CAM2), J. Geophys. Res., 108, 4035, doi:10.1029/2002JD002523, 2003. 